\title{
WestVirginiaUniversity
}

THE RESEARCH REPOSITORY @ WVU

Graduate Theses, Dissertations, and Problem Reports

1998

\section{Perturbation studies of excitable media}

\author{
Lisa Elizabeth Seagraves \\ West Virginia University
}

Follow this and additional works at: https://researchrepository.wvu.edu/etd

\section{Recommended Citation}

Seagraves, Lisa Elizabeth, "Perturbation studies of excitable media" (1998). Graduate Theses, Dissertations, and Problem Reports. 94.

https://researchrepository.wvu.edu/etd/94

This Thesis is protected by copyright and/or related rights. It has been brought to you by the The Research Repository @ WVU with permission from the rights-holder(s). You are free to use this Thesis in any way that is permitted by the copyright and related rights legislation that applies to your use. For other uses you must obtain permission from the rights-holder(s) directly, unless additional rights are indicated by a Creative Commons license in the record and/ or on the work itself. This Thesis has been accepted for inclusion in WVU Graduate Theses, Dissertations, and Problem Reports collection by an authorized administrator of The Research Repository @ WVU. For more information, please contact researchrepository@mail.wvu.edu. 


\title{
Perturbation Studies of Excitable Media
}

\author{
Lisa Elizabeth Seagraves
}

Thesis submitted to the Graduate School

of West Virginia University

in partial fulfillment of the requirements for

the degree of

Master of Science

in

Physical Chemistry

Kenneth Showalter, Chair

Charles Jaffè

Paul Jagodzinski

December 10, 1998

Morgantown, West Virginia

Keywords: Perturbation Studies

Copyright 1998, Lisa Elizabeth Seagraves 


\title{
Dedication
}

\author{
In love \\ I dedicate this thesis \\ to my parents
}

David R. and Gretchen L. Seagraves

For all your prayers, love, patience and support during these past years in school, Thank You!

But the God of all grace, who hath called us unto his eternal glory by Christ Jesus, after that ye have suffered a while, make you perfect, stablish, strengthen, settle you. To him be glory and dominion for ever and ever. Amen.

I Peter 5:10, 11 


\section{Acknowledgements}

I thank God for giving me the intelligence, determination, stamina, patience, and strength to make it to this point. I would like to thank my research advisor, Dr. Kenneth Showalter, for all your help during this time. You have such an excitement for research and teaching that it has made working with you a real joy! I would also like to thank my committee members, Dr. Paul Jagodzinski and Dr. Charles Jaffe, for your contributions to my thesis. Special thanks goes to Dr. Sándor Kádár and Dr. Jichang Wang. Without your help, I wouldn't have been able to finish so quickly. Thank you! Also, special thanks to my mentor, Dr. Raima Larter. Thank you for introducing me to the wonderful world of Chaos and Nonlinear Dynamics. I appreciate your support and friendship. Special thanks goes out to my mother and father for helping me get to this point. Thanks for your love, financial support and patience. I appreciate you being so supportive and understanding and letting me know I could make it when things got tough! Thanks to my best friend and brother, David. You have been so supportive of me and I really appreciate it! And finally, thanks to my family and friends for your love and support and financial help. 


\section{Table of Contents}

Page

Title Page $\ldots \ldots \ldots \ldots \ldots \ldots \ldots \ldots \ldots \ldots \ldots \ldots$

Dedication ..................... ii

Acknowledgements $\ldots \ldots \ldots \ldots \ldots \ldots$ iii

Table of Contents $\ldots \ldots \ldots \ldots \ldots \ldots \ldots \ldots$ iv

List of Tables $\ldots \ldots \ldots \ldots \ldots \ldots \ldots \ldots \ldots \ldots \ldots$ vi

List of Figures $\ldots \ldots \ldots \ldots \ldots \ldots \ldots \ldots \ldots \ldots$ vii

1. Introduction $\ldots \ldots \ldots \ldots \ldots \ldots \ldots \ldots \ldots$

2. Hydrogel Studies $\ldots \ldots \ldots \ldots \ldots$. . . . . . . . . . 15

2.1 Purpose $\ldots \ldots \ldots \ldots \ldots \ldots \ldots \ldots$

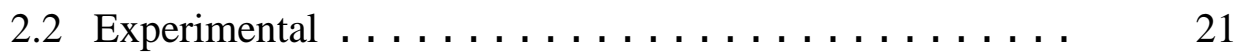

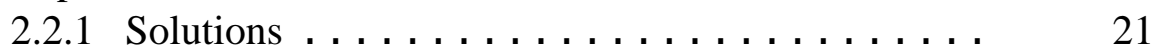

2.2 .2 Gels . . . . . . . . . . . . . . 22

2.2.2.1 Polyacrylamide/Bis-AA co-Aac gel . . . . . 22

2.2.2.2 Polyacrylamide/Bis-AA gel . . . . . . . . . . 23

2.2.2.3 Poly-isopropylacrylamide gel . . . . . . . . 24

2.2.2.4 Poly-isopropylacrylamide co-MAA gel . . . 24

2.2.2.5 Two layer gel . . . . . . . . . . . . . . . . . . . . 25

2.2 .3 Reaction set-ups . . . . . . . . . . . . . . 25

2.2.3.1 Continuous Flow Stirred Tank Reactor . . . 25

2.2.3.2 Spatial Pattern Studies . . . . . . . . . 27

2.2 .4 Experiments . . . . . . . . . . . . . . . . . . 27

2.2.4.1 FIS Oscillatory Experiments . . . . . . . 27

2.2.4.2 Spatial Pattern Studies . . . . . . . . . 28

2.3 Results . . . . . . . . . . . . . . . . . . . $\quad 28$

2.3.1 FIS Oscillatory Experiments . . . . . . . . . . . . . . 28

2.3.2 Spatial Pattern Studies . . . . . . . . . . . . 34

2.4 Discussion on FIS Reaction $\ldots \ldots \ldots \ldots \ldots \ldots$ 
3. Light Sensitive $\ldots \ldots \ldots \ldots \ldots \ldots \ldots \ldots \ldots \ldots \ldots$

3.1 Purpose $\ldots \ldots \ldots \ldots \ldots \ldots \ldots \ldots \ldots \ldots \ldots$

3.2 Experiments $\ldots \ldots \ldots \ldots \ldots \ldots \ldots \ldots \ldots \ldots \ldots$

3.2 .1 Gels $\ldots \ldots \ldots \ldots \ldots \ldots \ldots \ldots \ldots \ldots \ldots \quad 45$

3.2 .2 Solutions $\ldots \ldots \ldots \ldots \ldots \ldots \ldots \ldots \ldots \ldots \quad 45$

3.2 .3 Reaction set-up . . . . . . . . . . . . . 47

3.2.4 Experiments . . . . . . . . . . . . . $\quad 49$

3.2.4.1 BZ Reactions with Light Perturbations ... $\quad 49$

3.2.4.2 Self-Organized Criticality $\ldots \ldots \ldots \ldots . \quad 50$

3.2.4.3 Periodic Forcing $\ldots \ldots \ldots \ldots \ldots \ldots \quad 52$

4. Discussion $\ldots \ldots \ldots \ldots \ldots \ldots \ldots \ldots \ldots \ldots \ldots$

4.1 Self-Organized Criticality $\ldots \ldots \ldots \ldots \ldots \ldots \ldots \ldots$

4.2 Periodic Forcing $\ldots \ldots \ldots \ldots \ldots \ldots \ldots \ldots \ldots$

4.3 Conclusion $\ldots \ldots \ldots \ldots \ldots \ldots \ldots \ldots \ldots \ldots$

References $\ldots \ldots \ldots \ldots \ldots \ldots \ldots \ldots \ldots \ldots \ldots \ldots$

Abstract $\ldots \ldots \ldots \ldots \ldots \ldots \ldots \ldots \ldots \ldots \ldots \ldots \ldots \ldots \ldots \ldots$

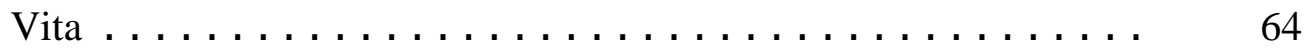

Approval of Examining Committee $\ldots \ldots \ldots \ldots \ldots \ldots \ldots$ 


\section{List of Tables}

Table Page

$1.1 \quad$ Four-Variable Model $\ldots \ldots \ldots \ldots \ldots$

$2.1 \quad$ Chemicals for the FIS Reaction $\ldots \ldots \ldots \ldots . \ldots \ldots$

$2.2 \quad$ Gel Preparations . . . . . . . . . . . . . . . 23

$2.3 \quad$ Flow Rates and Concentrations . . . . . . . . . . 30

$2.4 \quad$ Flow Rates and pH Ranges $\ldots \ldots \ldots \ldots$. . . . . . . . 31

2.5 Results of Spatial Pattern Experiments . . . . . . . . . . 34

$3.1 \quad$ Chemicals Used for the BZ Reaction . . . . . . . . . . . . 47

4.1 Reaction Conditions for SOC Experiments . . . . . . . 56

4.2 Reaction Conditions for Periodic Forcing . . . . . . . . 58 


\section{List of Figures}

Figure $\quad$ Page

1.1 Batch response in the iodate-sulfite system . . . . . . . 2

1.2 Oscillations in the iodate-sulfite-ferrocyanide system . . . . 4

1.3 $\mathrm{pH}$ as a function of time from the four-variable model . . . 8

$1.4 \mathrm{pH}$ as a function of time from the two-variable model $\ldots . . \quad 10$

1.5 Effect of illumination on oscillations . . . . . . . . . . 14

$2.1 \quad$ Apparatus for gels $\ldots \ldots \ldots \ldots \ldots$

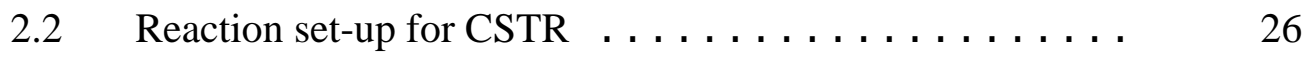

2.3 Reaction set-up for spatial pattern studies . . . . . . . . 29

$2.4 \mathrm{pH}$ oscillations in the FIS reaction $\ldots \ldots \ldots \ldots \ldots \ldots$

2.5 $\mathrm{pH}$ oscillations in the FIS reaction $\ldots \ldots \ldots \ldots \ldots$

3.1 Structure of the ruthenium complex $\ldots \ldots \ldots \ldots$. . . . 37

3.2 Image sequences showing influence of noise on wave propagation . . . . . . . . . . . . . 39

3.3 An array of blocks simulating the earthquake model . . . . 43

3.4 Set-up for silica gel preparations $\ldots \ldots \ldots \ldots$

3.5 Reaction set-up for light sensitive behavior studies . . . . . 48

3.6 Diagram for the 2-D array of cells . . . . . . . . . . 51

$4.1 \quad$ Power law for SOC experiments $\ldots \ldots \ldots \ldots$. . . . . 54

4.2 Pictorial diagram for wave volume calculations $\ldots \ldots . . .55$ 
4.3 A computer simulation of periodic forcing experiments . . . 59

-viii- 


\section{Chapter 1}

\section{Introduction}

Although iodate-based reactions were the first chemical oscillators to be discovered, little research has been done in comparison to the bromate-based reactions like the famous Belousov-Zhabotinsky (BZ) reaction. ${ }^{1}$ Hans Landolt was the first to initiate iodate-based studies, in his work in 1886. Eq 1.1 shows the reaction where iodic and sulfurous acids react in the presence of starch. ${ }^{2}$

$$
5 \mathrm{SO}_{3}{ }^{2-}+2 \mathrm{IO}_{3}{ }^{-}+2 \mathrm{H}^{+}=5 \mathrm{SO}_{4}{ }^{2-}+\mathrm{H}_{2} \mathrm{O}+\mathrm{I}_{2}
$$

After a certain amount of time, a blue color appears (starch is present to detect iodine), thus giving it the name of "Landolt Clock Reaction". In 1917, J. Eggert studied this complex reaction and found it to be made up of three successive stages given by eqs 1.21.4. ${ }^{2}$ The iodide ions formed in eq 1.2 are oxidized in eq 1.3 to free iodine, which is rapidly removed in eq 1.4 .

$$
\begin{aligned}
& \mathrm{IO}_{3}{ }^{-}+3 \mathrm{SO}_{3}{ }^{2-}=\mathrm{I}^{-}+3 \mathrm{SO}_{4}{ }^{2-} \\
& \mathrm{IO}_{3}{ }^{-}+5 \mathrm{I}^{-}+6 \mathrm{H}^{+}=3 \mathrm{I}_{2}+3 \mathrm{H}_{2} \mathrm{O} \\
& \mathrm{I}_{2}+\mathrm{SO}_{3}{ }^{2-}+\mathrm{H}_{2} \mathrm{O}=2 \mathrm{I}^{-}+\mathrm{SO}_{4}{ }^{2-}+2 \mathrm{H}^{+}
\end{aligned}
$$

When the sulfite ion concentration is reduced such that eq 1.4 becomes relatively slow, there will be enough free iodine to react with the starch to form the blue color.

Edblom, Orbán, and Epstein (EOE), 100 years later in 1986, studied the Landolt Clock Reaction further and found that the iodate oxidation of sulfite in a continuous flow 


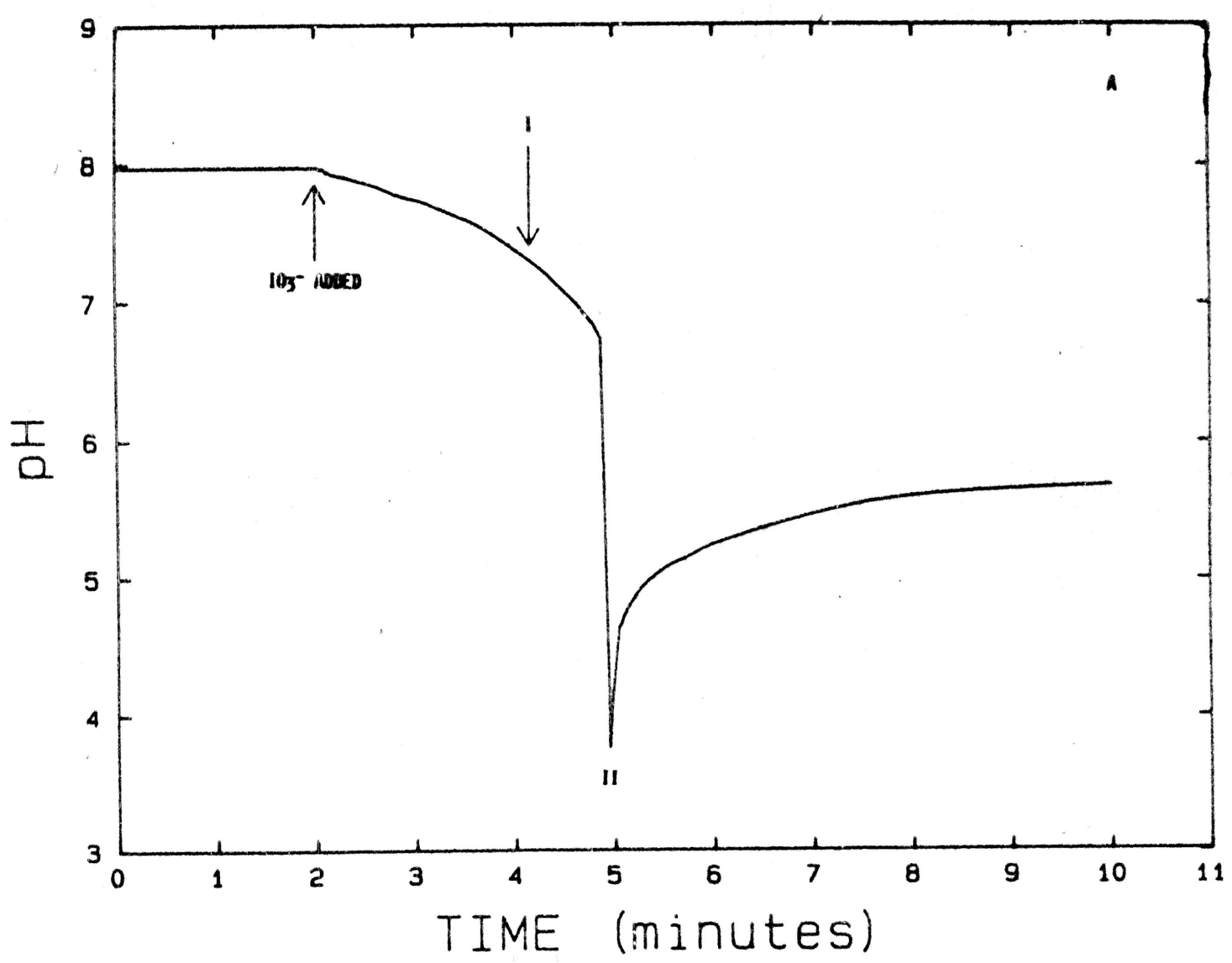

Figure 1.1. Batch response in the iodate-sulfite system, $\left[\mathrm{IO}_{3}{ }^{-}\right]=0.0715 \mathrm{M}$, $\left[\mathrm{SO}_{3}{ }^{2-}\right]=0.0865 \mathrm{M},\left[\mathrm{H}_{2} \mathrm{SO}_{4}\right]=0.00506 \mathrm{M}, \mathrm{T}=30^{\circ} \mathrm{C}$. Figure from Ref 1 . 
stirred tank reactor (CSTR) becomes oscillatory in $\mathrm{pH}$ when ferrocyanide is added. "The discovery by EOE represents the first example of sustained oscillations in a Landolt type system". ${ }^{3}$ EOE used eqs 1.2-1.4 to develop a component process model for the reaction. Equation 1.2 is initially dominant $\mathrm{as} \mathrm{IO}_{3}{ }^{-}$is added and the $\mathrm{pH}$ of the reaction begins to slightly decrease, as can be seen in Figure 1.1. At point I in this figure, more $\mathrm{I}^{-}$is produced and eqs 1.3 and 1.4 become dominant. To better understand what happens next, eq 1.5 is introduced as a combination of eqs 1.3 and $1.4((1.3)+3 \times(1.4)) .{ }^{1}$

$$
\mathrm{IO}_{3}{ }^{-}+3 \mathrm{HSO}_{3}{ }^{-}+5 \mathrm{I}^{-}+6 \mathrm{H}^{+} \rightarrow 6 \mathrm{I}^{-}+3 \mathrm{SO}_{4}{ }^{2-}+9 \mathrm{H}^{+}
$$

Because $\mathrm{I}^{-}$and $\mathrm{H}^{+}$are produced autocatalytically, the reaction rate increases with increasing concentrations of these species. The $\mathrm{pH}$ begins to decrease, as can be seen in Figure 1.1, because of the $\mathrm{H}^{+}$ions produced. At point II in Figure 1.1, all of the $\mathrm{HSO}_{3}{ }^{-}$ has been consumed and $I_{2}$ accumulates, as is evident by the color change in the reaction from colorless to brown. After point II, only eq 1.3 is possible; the $\mathrm{H}^{+}$ions are consumed and the $\mathrm{pH}$ rises.

In order for oscillations to occur in this reaction, a reactant (ferrocyanide) has to be introduced that regenerates iodide from iodine. Ferrocyanide reacts with the $\mathrm{I}_{2}$ that is formed from above to produce ferricyanide according to eq $1.6 .{ }^{1}$

$$
\mathrm{I}_{2}+2 \mathrm{Fe}(\mathrm{CN})_{6}^{4-} \rightarrow 2 \mathrm{I}^{-}+2 \mathrm{Fe}(\mathrm{CN})_{6}^{3-}
$$

Ferricyanide acts as an inhibitor to the Landolt system and gives the CSTR reaction the needed time to replenish reactants to restart the next oscillation.

$$
2 \mathrm{Fe}(\mathrm{CN})_{6}{ }^{3-}+\mathrm{SO}_{3}{ }^{2-}+\mathrm{H}_{2} \mathrm{O} \rightarrow 2 \mathrm{Fe}(\mathrm{CN})_{6}{ }^{4-}+\mathrm{SO}_{4}{ }^{2-}+2 \mathrm{H}^{+}
$$

Equation $1.7^{1}$ shows how ferricyanide is consumed and the reaction begins again. These oscillations can be seen in Figure 1.2. ${ }^{1}$ 


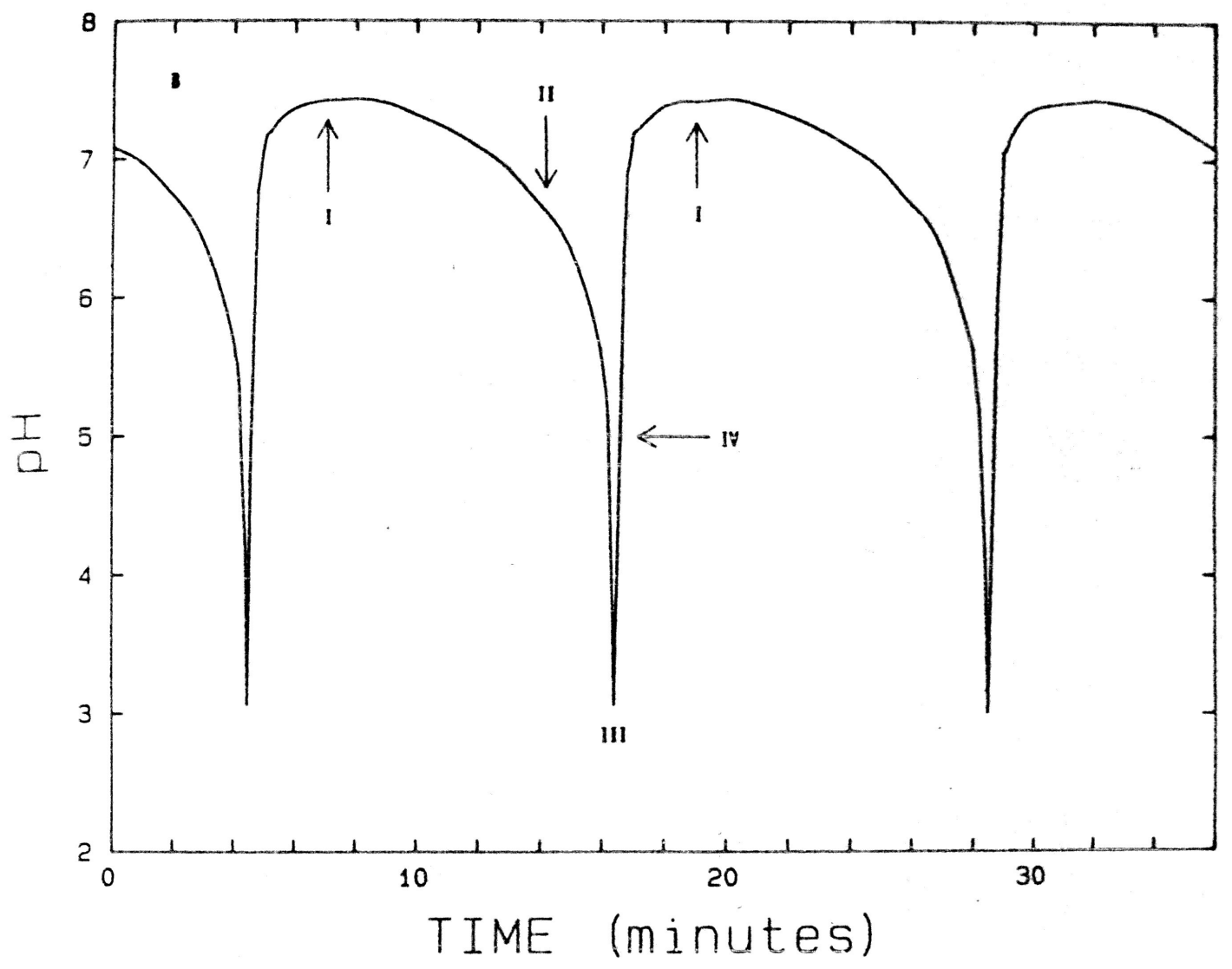

Figure 1.2. Oscillations in the iodate-sulfite-ferrocyanide system at $40^{\circ} \mathrm{C}$, $\left[\mathrm{IO}_{3}{ }^{-}\right]_{\mathrm{o}}=0.075 \mathrm{M},\left[\mathrm{SO}_{3}{ }^{2-}\right]_{\mathrm{o}}=0.0893 \mathrm{M},\left[\mathrm{Fe}(\mathrm{CN})_{6}{ }^{4-}\right]_{\mathrm{o}}=0.0204 \mathrm{M}$, $\left[\mathrm{H}_{2} \mathrm{SO}_{4}\right]_{\mathrm{o}}=0.0045 \mathrm{M}, \mathrm{k}_{\mathrm{o}}=0.0022 \mathrm{~s}^{-1}$. Figure from Ref 1 . 
In 1987, Gáspár et al. took the Landolt system one step further, by developing a model of the EOE system. ${ }^{3}$ They found that by combining the processes of the EOE scheme with the corresponding rate laws and constants found in the literature, they were able to develop an empirical rate law model (ERL) based on the stoichiometry and kinetics of each process. This model was, however, non-oscillatory. A buffer system (Table 1.1, process E) was then added to the ERL model and the system became oscillatory in $\mathrm{pH}$ similar to that obtained experimentally. The left side of Table 1 shows the five processes that make up the ERL model. Process A, the Dushman reaction, is the iodate oxidation of iodide. Process B, studied by Bünau and Eigen, ${ }^{5}$ is the iodine oxidation of bisulfite. Process C, studied by Reynolds, ${ }^{6}$ is the iodine oxidation of ferrocyanide. Process D is the uncatalyzed direct reaction between iodate and bisulfite. Finally, process $\mathrm{E}$ is the buffer system that was added to the model to allow for oscillatory behavior. This process is the weak acid equilibrium of the oxysulfur species. After this 10-variable model was constructed, it was then reduced so that the dynamical behavior of the oscillatory EOE reaction could be better understood. In Table 1.1 , the chemical species in braces are treated as constants, since their concentrations are either in large excess or vary little with each oscillation. These species are, therefore, incorporated into the rate constants in the reduction. After this reduction and stoichiometric reductions, eqs N1-N5 are obtained, as shown in Table 1.1. In eqs N1-N5, A represents $\mathrm{SO}_{3}{ }^{2-}, \mathrm{X}$ represents $\mathrm{HSO}_{3}{ }^{-}, \mathrm{Y}$ represents $\mathrm{H}^{+}$, and $\mathrm{Z}$ represents $\mathrm{I}_{2}$. The differential equations corresponding to the four-variable model are given by eqs 1.8-1.11. 
Table 1.1: Four-Variable Model ${ }^{4}$

Process A

$$
\begin{aligned}
& \left\{\mathrm{IO}_{3}^{-}\right\}+\left\{5 \mathrm{I}^{-}\right\}+6 \mathrm{H}^{+} \stackrel{k_{\alpha 2}}{\longrightarrow} 3 \mathrm{I}_{2}+\left\{3 \mathrm{H}_{2} \mathrm{O}\right\} \\
& v_{\alpha}=-\frac{1}{6} \mathrm{~d}\left[\mathrm{H}^{+}\right] / \mathrm{dt}=\frac{1}{3} \mathrm{~d}\left[\mathrm{I}_{2}\right] / \mathrm{dt} \\
& v_{\alpha}=\left\{k_{\alpha 2}\left(C_{\mathrm{IO}_{3}^{-}}\right)\left(C_{\mathrm{I}}\right)^{2}\right\}\left[\mathrm{H}^{+}\right]^{2}
\end{aligned}
$$

$$
\begin{gathered}
6 \mathrm{Y} \underset{\alpha^{\prime}}{\stackrel{\mathrm{k}^{\prime}}{\longrightarrow}} 3 \mathrm{Z} \\
v_{\alpha^{\prime}}=-\frac{1}{6} \mathrm{dY} / \mathrm{dt}=\frac{1}{3} \mathrm{dZ} / \mathrm{dt} \\
v_{\alpha^{\prime}}=k_{\alpha^{\prime}} \mathrm{Y}^{2} \\
2 \mathrm{Y} \stackrel{\mathrm{k}_{\mathrm{N} 3}}{\longrightarrow} \mathrm{Z} \\
v_{\mathrm{N} 3}=-\frac{1}{2} \mathrm{dY} / \mathrm{dt}=\mathrm{dZ} / \mathrm{dt} \\
v_{\mathrm{N} 3}=3 k_{\alpha^{\prime}} \mathrm{Y}^{2}=k_{\mathrm{N} 3} \mathrm{Y}^{2}
\end{gathered}
$$

Process B

$$
\begin{array}{ll}
\mathrm{I}_{2}+\mathrm{HSO}_{3}^{-}+\left\{\mathrm{H}_{2} \mathrm{O}\right\} \stackrel{k_{\beta}}{\longrightarrow}\left\{2 \mathrm{I}^{-}\right\}+\left\{\mathrm{SO}_{4}^{2-}\right\}+3 \mathrm{H}^{+} & \mathrm{Z}+\mathrm{X} \stackrel{k_{\mathrm{N} 4}}{\longrightarrow} 3 \mathrm{Y} \\
v_{\beta}=k_{\beta}\left[\mathrm{I}_{2}\right]\left[\mathrm{HSO}_{3}^{-}\right] & v_{\mathrm{N} 4}=k_{\mathrm{N} 4} \mathrm{ZX}
\end{array}
$$

Process C

$$
\begin{array}{lc}
\mathrm{I}_{2}+\left\{2 \mathrm{Fe}(\mathrm{CN})_{6}^{4-}\right\} \stackrel{k_{\gamma}}{\longrightarrow}\left\{2 \mathrm{I}^{-}\right\}+\left\{2 \mathrm{Fe}(\mathrm{CN})_{6}^{3-}\right\} & \mathrm{Z} \stackrel{k_{\mathrm{N} 5}}{\longrightarrow} \\
v_{\gamma}=k_{\gamma}\left[\mathrm{I}_{2}\right] C_{\mathrm{Fe}(\mathrm{CN})_{6}^{4-}} & v_{\mathrm{N} 5}=k_{\mathrm{N} 5} \mathrm{Z}
\end{array}
$$

Process D

$$
\begin{aligned}
& \left\{\mathrm{IO}_{3}^{-}\right\}+3 \mathrm{HSO}_{3}^{-} \stackrel{k_{\delta}}{\longrightarrow}\left\{\mathrm{I}^{-}\right\}+\left\{3 \mathrm{SO}_{4}^{2-}\right\}+3 \mathrm{H}^{+} \\
& v_{\delta}=-\frac{1}{3} \mathrm{~d}\left[\mathrm{HSO}_{3}^{-}\right] / \mathrm{dt}=\frac{1}{3} \mathrm{~d}\left[\mathrm{H}^{+}\right] / \mathrm{dt} \\
& v_{\delta}=k_{\delta} C_{\mathrm{IO}_{3}^{-}}\left[\mathrm{HSO}_{3}^{-}\right]
\end{aligned}
$$

$$
\begin{gathered}
3 \mathrm{X} \stackrel{k_{\delta^{\prime}}}{\longrightarrow} 3 \mathrm{Y} \\
v_{\delta^{\prime}}=-\frac{1}{3} \mathrm{dX} / \mathrm{dt}=\frac{1}{3} \mathrm{dY} / \mathrm{dt} \\
v_{\delta^{\prime}}=k_{\delta^{\prime}} \mathrm{X} \\
\mathrm{X} \stackrel{k_{\mathrm{N} 2}}{\longrightarrow} \mathrm{Y} \\
v_{\mathrm{N} 2}=-\mathrm{dX} / \mathrm{dt}=\mathrm{dY} / \mathrm{dt} \\
v_{\mathrm{N} 2}=3 k_{\delta^{\prime}} \mathrm{X}=k_{\mathrm{N} 2} \mathrm{X}
\end{gathered}
$$

Process E

$$
\begin{array}{lc}
\mathrm{SO}_{3}^{2-}+\mathrm{H}^{+} \stackrel{k_{\varepsilon 2} / k_{-\varepsilon 2}}{\longleftrightarrow} \mathrm{HSO}_{3}^{-} & \mathrm{A}+\mathrm{Y} \stackrel{k_{\mathrm{N} 1} / k_{-\mathrm{N} 1}}{\longrightarrow} \mathrm{X} \\
v_{\varepsilon 2}=k_{\varepsilon 2}\left[\mathrm{SO}_{3}^{2-}\right]\left[\mathrm{H}^{+}\right] & v_{\mathrm{N} 1}=k_{\mathrm{N} 1} \mathrm{AY} \\
v_{-\varepsilon 2}=k_{-\varepsilon 2}\left[\mathrm{HSO}_{3}^{-}\right] & v_{-\mathrm{N} 1}=k_{-\mathrm{N} 1} \mathrm{X}
\end{array}
$$




$$
\begin{gathered}
\mathrm{dX} / \mathrm{dt}=\mathrm{k}_{\mathrm{N} 1} \mathrm{AY}-\mathrm{k}_{-\mathrm{N} 1} \mathrm{X}-\mathrm{k}_{\mathrm{N} 2} \mathrm{X}-\mathrm{k}_{\mathrm{N} 4} \mathrm{ZX}-\mathrm{k}_{\mathrm{o}} \mathrm{X} \\
\mathrm{dY} / \mathrm{dt}=-\mathrm{k}_{\mathrm{N} 1} \mathrm{AY}+\mathrm{k}_{-\mathrm{N} 1} \mathrm{X}+\mathrm{k}_{\mathrm{N} 2} \mathrm{X}-2 \mathrm{k}_{\mathrm{N} 3} \mathrm{Y}^{2}+3 \mathrm{k}_{\mathrm{N} 4} \mathrm{ZX}+\mathrm{k}_{\mathrm{o}}\left(\mathrm{Y}_{\mathrm{o}}-\mathrm{Y}\right) \\
\mathrm{dZ} / \mathrm{dt}=\mathrm{k}_{\mathrm{N} 3} \mathrm{Y}^{2}-\mathrm{k}_{\mathrm{N} 4} \mathrm{ZX}-\mathrm{k}_{\mathrm{N} 5} \mathrm{Z}-\mathrm{k}_{\mathrm{o}} \mathrm{Z} \\
\mathrm{dA} / \mathrm{dt}=-\mathrm{k}_{\mathrm{N} 1} \mathrm{AY}+\mathrm{k}_{-\mathrm{N} 1} \mathrm{X}+\mathrm{k}_{\mathrm{o}}\left(\mathrm{A}_{\mathrm{o}}-\mathrm{A}\right)
\end{gathered}
$$

In eqs 1.8-1.11, $\mathrm{k}_{\mathrm{o}}$ represents the flow rate, $\mathrm{Y}_{\mathrm{o}}$ represents the initial hydrogen ion concentration, and $\mathrm{A}_{\mathrm{o}}$ represents the initial sulfite concentration. As can be seen in Figure 1.3, the oscillatory behavior of the four-variable model is very similar to that of the experiment (see Figure 1.2 for comparison).

To further reduce this model, eqs 1.8-1.11 are rewritten as eqs 1.12-1.15 in terms of the dimensionless variables $\mathrm{a}, \mathrm{x}, \mathrm{y}$, and $\mathrm{z}$ and time $\tau$.

$$
\begin{aligned}
& \mathrm{dx} / \mathrm{d} \tau=\text { ay }-\mathrm{x}-\mathrm{xz}-\xi \mathrm{x} \\
& \mathrm{dy} / \mathrm{d} \tau=-\mathrm{ay}+\mathrm{x}-\mathrm{y}^{2}+3 \mathrm{xz}-\xi \mathrm{y}+\eta \mathrm{Y}_{\mathrm{o}} \\
& \mathrm{dz} / \mathrm{d} \tau=\psi \mathrm{y}^{2}-2 \psi \mathrm{xz}-\kappa \mathrm{z}-\xi_{\mathrm{z}} \\
& \mathrm{da} / \mathrm{d} \tau=-\lambda \mathrm{ay}+\lambda \mu \mathrm{x}-\xi \mathrm{a}+\lambda \eta \mathrm{A}_{\mathrm{o}}
\end{aligned}
$$

In eqs 1.12-1.15, $\mathrm{A}_{\mathrm{o}}$ and $\mathrm{Y}_{\mathrm{o}}$ are the same as described above and the parameters are defined below.

$$
\begin{aligned}
& \mathrm{k}_{\mathrm{o}}=1.5 \times 10^{-3} \mathrm{~s}^{-1} \\
& \xi=\mathrm{k}_{\mathrm{o}} /\left(\mathrm{k}_{-\mathrm{N} 1}+\mathrm{k}_{\mathrm{N} 2}\right)=1.9 \times 10^{-7} \\
& \eta=2 \mathrm{k}_{\mathrm{o}} \mathrm{k}_{\mathrm{N} 3} /\left(\mathrm{k}_{-\mathrm{N} 1}+\mathrm{k}_{\mathrm{N} 2}\right)^{2}=3.4 \times 10^{-6} \mathrm{M}^{-1} \\
& \psi=\mathrm{k}_{\mathrm{N} 4} / 4 \mathrm{k}_{\mathrm{N} 3}=7.7 \times 10^{3} \\
& \kappa=\mathrm{k}_{\mathrm{N} 5} /\left(\mathrm{k}_{-\mathrm{N} 1}+\mathrm{k}_{\mathrm{N} 2}\right)=3.7 \times 10^{-3} \\
& \lambda=\mathrm{k}_{\mathrm{N} 1} / 2 \mathrm{k}_{\mathrm{N} 3}=3.3 \times 10^{5} \\
& \mu=\mathrm{k}_{-\mathrm{N} 1} /\left(\mathrm{k}_{-\mathrm{N} 1}+\mathrm{k}_{\mathrm{N} 2}\right)=1.0
\end{aligned}
$$




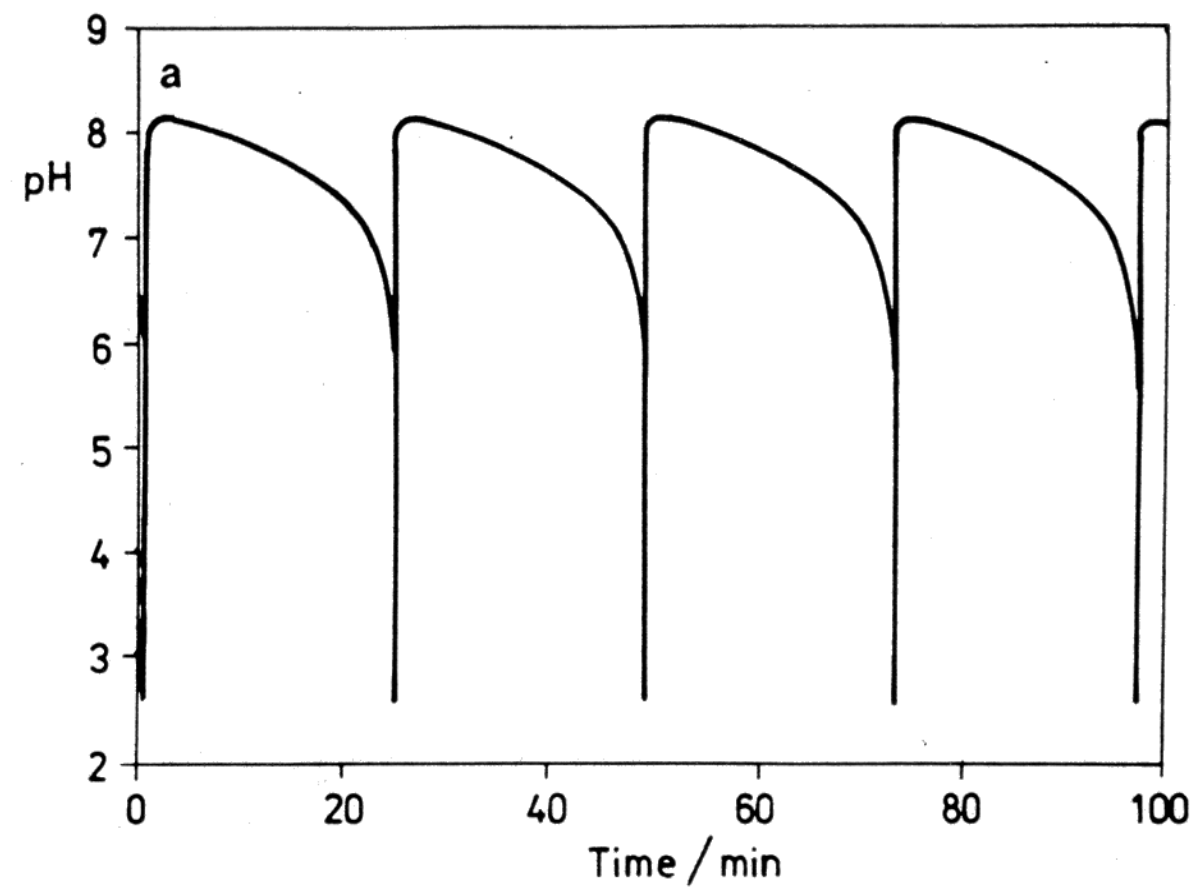

Figure 1.3. $\mathrm{pH}$ as a function of time from the four-variable model N1-N5. Figure from Ref 4. 
Gaspar and Showalter ${ }^{4}$ found the variable a from eqs $1.12-1.15$ to be a fast variable, meaning that it relaxes more rapidly than $\mathrm{x}$ and $\mathrm{y}$ and it can be approximated as an instantaneous function of these variables. Therefore, setting eq 1.15 equal to zero, the three-variable model is obtained, with $\mathrm{a}(\mathrm{x}, \mathrm{y})$ given by eq 1.16 . This model exhibits

$$
a(x, y)=\frac{\lambda \eta \mathrm{A}_{\circ}+\lambda \mu x}{\xi+\lambda y}
$$

dynamical behavior similar to the four-variable model. After examining eqs 1.12-1.15 again, it was found that $\mathrm{z}$ relaxes on a time scale comparable to the fast variable a. Equation 1.14 was therefore set to zero and the two-variable model reduction is obtained, with $\mathrm{z}(\mathrm{x}, \mathrm{y})$ given by eq 1.17 . The three-variable model is, therefore, an intermediate

$$
z(x, y)=\frac{\psi y^{2}}{2 \psi x+\kappa+\xi}
$$

model. The dynamical behavior of the two-variable model is also similar to that of experiment (compare Figure 1.4 with 1.2). Although the period of the oscillations differs in comparison, the two-variable model still exhibits $\mathrm{pH}$ oscillations in the correct range.

The Belousov-Zhabotinsky (BZ) reaction is the most widely studied oscillatory system. The reaction consists of the oxidation of an organic species, such as malonic acid, by acidified bromate in the presence of a metal ion catalyst. This metal ion catalyst is most often either $[\mathrm{Fe}(\mathrm{II})(\mathrm{phen})]^{2+} /[\mathrm{Fe}(\mathrm{III})(\mathrm{phen})]^{3+}$ (commonly referred to as ferriin/ferroin) or $\mathrm{Ce}(\mathrm{III}) / \mathrm{Ce}(\mathrm{IV}) .^{7}$ The BZ system is made up of many complex 


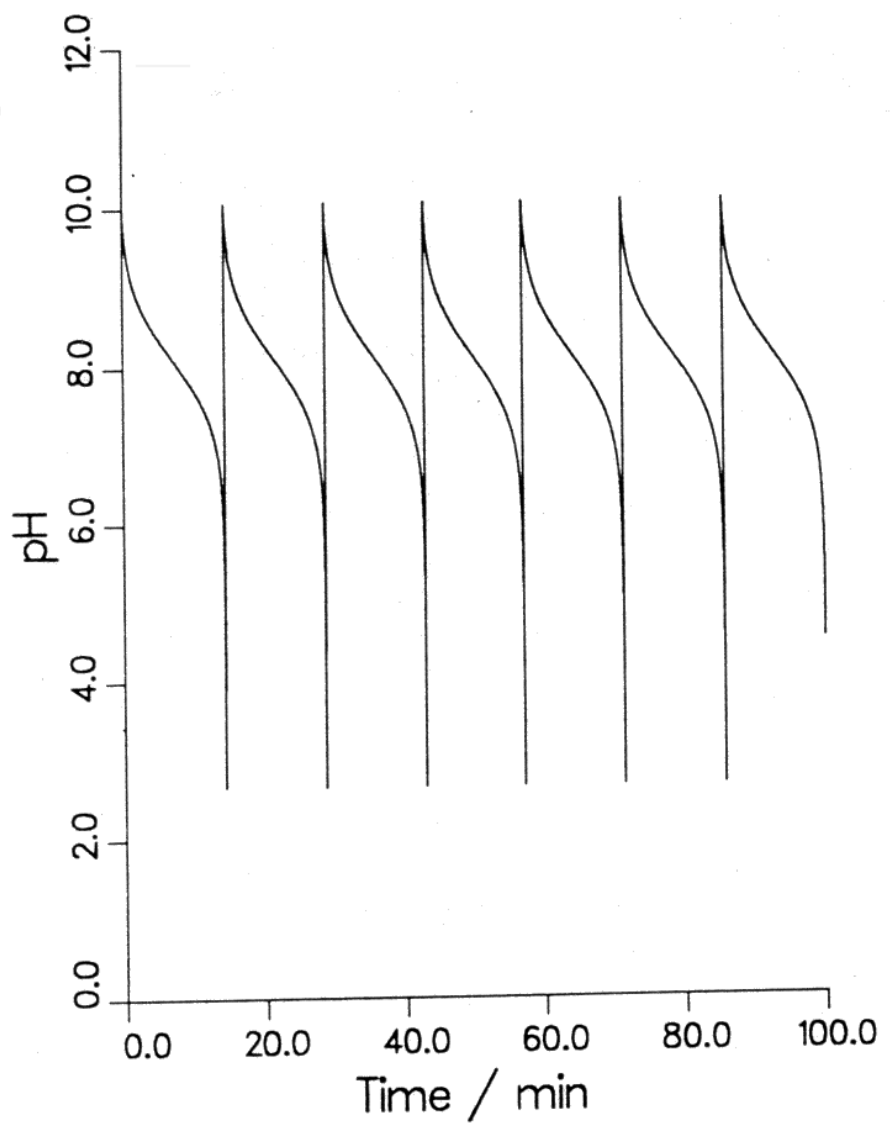

Figure 1.4. $\mathrm{pH}$ as a function of time calculated from the two-variable reduction of model N1-N5. Figure from Ref 4. 
reactions, which can be understood by a highly simplified mechanism, the Field-KörösNoyes (FKN) mechanism. This mechanism is given by eqs $1.18-1.27 .{ }^{8}$

$$
\begin{aligned}
& \mathrm{HOBr}+\mathrm{Br}^{-}+\mathrm{H}^{+} \leftrightarrow \mathrm{Br}_{2}+\mathrm{H}_{2} \mathrm{O} \\
& \mathrm{HBrO}_{2}+\mathrm{Br}^{-}+\mathrm{H}^{+} \rightarrow 2 \mathrm{HOBr} \\
& \mathrm{BrO}_{3}^{-}+\mathrm{Br}^{-}+2 \mathrm{H}^{+} \rightarrow \mathrm{HBrO}_{2}+\mathrm{HOBr} \\
& 2 \mathrm{HBrO}_{2} \rightarrow \mathrm{BrO}_{3}^{-}+\mathrm{HOBr}+\mathrm{H}^{+} \\
& \mathrm{BrO}_{3}{ }^{-}+\mathrm{HBrO}_{2}+\mathrm{H}^{+} \leftrightarrow 2 \mathrm{BrO}_{2} \cdot+\mathrm{H}_{2} \mathrm{O} \\
& \mathrm{BrO}_{2} \cdot+\mathrm{Ce}^{3+}+\mathrm{H}^{+} \leftrightarrow \mathrm{HBrO}_{2}+\mathrm{Ce}^{4+} \\
& \mathrm{BrO}_{2} \cdot+\mathrm{Ce}^{4+}+\mathrm{H}_{2} \mathrm{O} \rightarrow \mathrm{BrO}_{3}^{-}+\mathrm{Ce}^{3+}+2 \mathrm{H}^{+} \\
& \mathrm{Br}_{2}+\mathrm{CH}_{2}(\mathrm{COOH})_{2} \rightarrow \mathrm{BrCH}(\mathrm{COOH})_{2}+\mathrm{Br}^{-}+\mathrm{H}^{+} \\
& 6 \mathrm{Ce}^{4+}+\mathrm{CH}_{2}(\mathrm{COOH})_{2}+2 \mathrm{H}_{2} \mathrm{O} \rightarrow 6 \mathrm{Ce}^{3+}+\mathrm{HCOOH}+2 \mathrm{CO}_{2}+6 \mathrm{H}^{+} \\
& 4 \mathrm{Ce}^{4+}+\mathrm{BrCH}(\mathrm{COOH})_{2}+2 \mathrm{H}_{2} \mathrm{O} \rightarrow \mathrm{Br}^{-}+4 \mathrm{Ce}^{3+}+\mathrm{HCOOH}+2 \mathrm{CO}_{2}+5 \mathrm{H}^{+}
\end{aligned}
$$

Field and Noyes developed a mathematical model of the FKN mechanism in a model called the Oregonator given by eqs $1.28-1.32 .^{9}$

$$
\begin{aligned}
& \mathrm{A}+\mathrm{Y} \rightarrow \mathrm{X}+\mathrm{P} \\
& \mathrm{X}+\mathrm{Y} \rightarrow 2 \mathrm{P} \\
& \mathrm{A}+\mathrm{X} \rightarrow 2 \mathrm{X}+2 \mathrm{Z} \\
& 2 \mathrm{X} \rightarrow \mathrm{A}+\mathrm{P} \\
& \mathrm{B}+\mathrm{Z} \rightarrow \text { Y }
\end{aligned}
$$

In the above reactions, $\mathrm{A}=\mathrm{BrO}_{3}{ }^{-}, \mathrm{B}=$ organic substrate $+\mathrm{BrMA}, \mathrm{P}=\mathrm{HOBr}, \mathrm{X}=\mathrm{HBrO}_{2}$, $\mathrm{Y}=\mathrm{Br}^{-}$, and $\mathrm{Z}=$ oxidized metal catalyst. Krug et al. ${ }^{10}$ used the Oregonator model with modifications to study the oxygen sensitivity and photosensitivity of the BZ reaction. 
Their changes from the above equations include replacing eq 1.32 with eq 1.33 and adding eq 1.34 , where $\mathrm{h}$ is a stoichiometric factor and $\Phi$ is the bromide production from both oxygen and photochemical effects.

$$
\begin{aligned}
& \mathrm{Z} \rightarrow \mathrm{hY} \\
& \stackrel{\Phi}{\longrightarrow} \mathrm{Y}
\end{aligned}
$$

Krug et al. found that by adding eq 1.34 , this model is able to show bistable regions similar to that shown in experimental studies. This model also shows oscillations. The oxygen affects the system by causing a transition between the oscillatory state and the excitable state. Photochemical effects include altering and/or inhibiting wave activity, depending on the intensity of the light. ${ }^{11}$ The photochemical effects on the Oregonator model were studied by Kádár et al. ${ }^{12}$ Their system, catalyzed by the tris(2,2'bipyridine)ruthenium(II) complex, $\mathrm{Ru}(\mathrm{bpy})_{3}{ }^{2+}$, follows the first four equations of the Oregonator listed above, with eqs 1.35-1.37 added, where $\mathrm{M}=$ malonic acid, $\mathrm{Z}=\mathrm{Ru}(\mathrm{III})$, $\mathrm{V}=$ bromomalonic acid, $\mathrm{E}=\mathrm{Ru}(\mathrm{bpy})_{3}{ }^{2+}, \mathrm{Y}=\mathrm{Br}^{-}$, and $\mathrm{A}=\mathrm{BrO}_{3}{ }^{-}$.

$$
\begin{aligned}
& \mathrm{M}+\mathrm{Z} \rightarrow \mathrm{hY} \\
& \mathrm{E}+\mathrm{V} \rightarrow \mathrm{Y}+\mathrm{Z} \\
& \mathrm{E}+\mathrm{A} \rightarrow \mathrm{X}+2 \mathrm{Z}
\end{aligned}
$$

They found that not only does the intensity of the light affect the oscillatory behavior, but also the concentration of the bromomalonic acid (BrMA) plays an important role in the photosensitivity. At a light intensity of $5 \mathrm{~V}$ (on a PMT scale) and a BrMA concentration of $0.05 \mathrm{M}$, wave activity is inhibited for the duration of the illumination, and then oscillations continue. This behavior is also seen in the experimental studies of the BZ 
reaction. This behavior can be seen in Figure 1.5. Reddy et al. ${ }^{13}$ found that not only is wave activity inhibited by illumination, but variations of the thickness of the solution layer also has an affect on inhibition of wave activity. The thinner the solution layer the more light is able to inhibit waves. In the studies of Petrov et al., ${ }^{14}$ it was found that by altering the bromate concentrations in the illuminated system, four types of results were found: the waves were inhibited, the wave speed was increased, the wave speed was decreased, and target patterns were formed. Studies of light effects in the ruthenium catalyzed BZ reaction allows the possibility of producing predetermined, spatially inhomogeneous behavior ${ }^{15}$ by suppressing wave activity. ${ }^{12}$ 

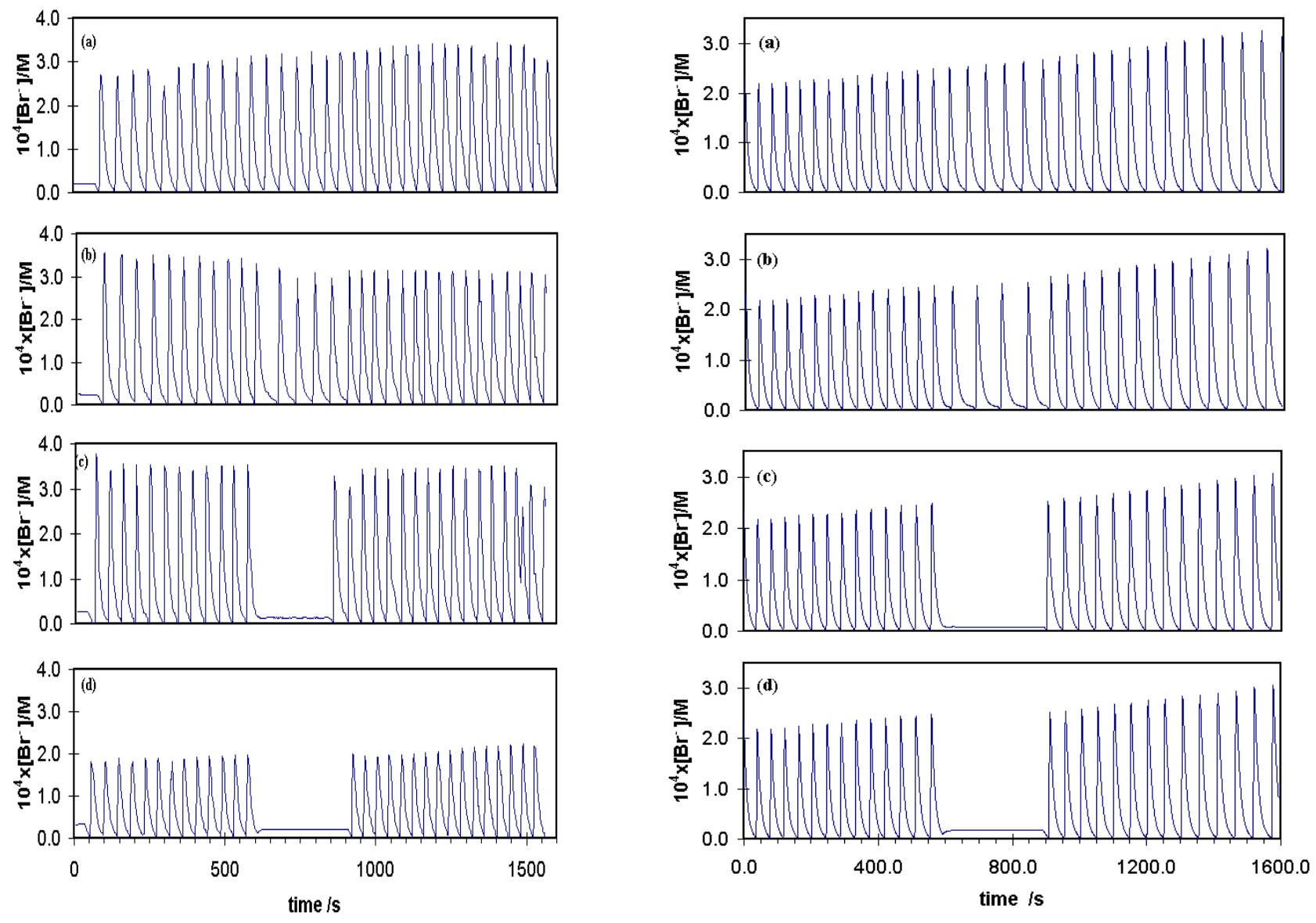

Figure 1.5. Effect of illumination on oscillations at a light intensity of $5 \mathrm{~V}$. Left: Effects in the BZ system. The BrMA concentrations are 0.010 M (a), 0.020 M (b), 0.025 M (c), and 0.050 M (d), respectively. Right: Effects in modified Oregonator model. The BrMA concentrations are 0.01 M (a), 0.02 M (b), 0.03 M (c), and 0.05 M (d), respectively.

Figure from Ref 12 . 


\section{Chapter 2 \\ Hydrogel Studies}

\subsection{Purpose}

Polymer gels have attracted much interest because of their dramatic response to the change of an external factor such as $\mathrm{pH},{ }^{16}$ temperature, ${ }^{17-19}$ electric field, ${ }^{20-22}$ and light. ${ }^{16,23}$ The large change in volume due to these factors results in peculiar mechanical and chemical properties. ${ }^{20,24}$

These gels consist of a three-dimensional cross-linked polymer network exposed to some solvent or solution. The continuous or discontinuous transition, volume phase transition, ${ }^{25}$ occurs between the swollen and collapsed states, the two states in which the gels can exist. The volume phase transition of gels observed so far can be classified into four classes according to the driving forces of the phase transition: van der Waals force, hydrogen bonding, hydrophobic interaction, and electrostatic interaction of charges on the polymer chain. ${ }^{18}$

Because these polymers exhibit such dramatic swelling-collapsing behavior, they have the potential for a diverse variety of applications. The $\mathrm{pH}$-sensitivity suggests possible applications in $\mathrm{pH}$-specific membrane separations, solvent recovery, and improved purification in pharmaceutical processes. Some hydrogels exhibit unique on/off diffusional behavior controlling solute diffusion. ${ }^{26,27}$ By changing diffusion properties as a response to changes in physiological conditions and the advantageous combined effect of thermal and $\mathrm{pH}$-sensitivity, hydrogels have been studied and applied as controlled drug delivery devices. ${ }^{28}$ 
As a response to the change in environmental factors, hydrogels undergo shape change and develop a contractile force responding to outside stimulus. Systems with this unique feature are frequently referred to as "Chemomechanical systems". ${ }^{29}$ This refers to thermodynamic systems capable of transforming chemical energy directly into mechanical energy. The isothermal conversion of all living organisms can be easily seen; e.g. in muscle, flagella, and ciliary movement. Osada et $\mathrm{al}^{29}$ developed a chemomechanical 'muscle' based on polyacrylamide hydrogel that was capable of lifting its own weight as a response to an applied electric field. Also, Osada et al. ${ }^{20}$ developed a gel system that had a surfactant selectively adsorbed on one side and was capable of contraction with significant curvature. With the mounted pawls on the ends of the gel, it was able to move with a ratchet-like mechanism with speeds up to $25 \mathrm{~cm} / \mathrm{min}$.

For these gel systems an external stimulus is necessary to cause the action of the gel. However, many physiological systems maintain autonomous cyclic changes in a nonequilibrium state. Introducing self-oscillation into the gel systems will open new possibilities in developing novel biomimetic intelligent materials exhibiting rhythmical actions. Self-oscillation can be provided by appropriate chemical systems in which $\mathrm{pH}$ or redox potential changes periodically, providing the periodically changing environment for the polymer network. A further step in this direction would be a system that spontaneously develops dynamical activity in a stationary, non-changing environment. ${ }^{15}$ The resemblance to a living organism is even more obvious: the system extracts chemical energy from the stationary environment and turns it into chemomechanical work.

Poly(N-isopropylacrylamide) (PNIPA) based systems are the most often studied chemomechanical system due to their temperature ${ }^{17,19}$ and $\mathrm{pH}$-sensitivity. ${ }^{16}$ The 
incorporation of hydrophilic chains into the polymer network improves the $\mathrm{pH}$ sensitivity significantly. The PNIPA network itself is rather hydrophobic; therefore, the polymer network is not very sensitive to $\mathrm{pH}$ or ionic strength changes. However, if hydrophilic chains are incorporated into the network, the three-dimensional structure greatly depends on the $\mathrm{pH}$ environment via electrostatic and van der Waals interactions. The hydrophilic chain is usually introduced with the co-polymerization with acrylamide forming PNIPAPAAM co-polymer. During the treatment following the polymerization, the amide group partially hydrolyzes and forms carboxylic acid groups attached to the chain. The state of these groups strongly depends on the $\mathrm{pH}$ of the environment. At low $\mathrm{pH}$ they are in the protonated form and the network is in a collapsed state with very little water uptake. At high $\mathrm{pH}$, however, they are in the anionic form and they repel each other, resulting in an expanded network with a large water uptake. The volume change due to the change in $\mathrm{pH}$ from 4 to 9 can be as high as 20 fold. ${ }^{27}$ Such a change in structure will influence diffusion of molecules through the gel matrix. Indeed, there is evidence that diffusion through the polymer network may depend on the state of the matrix. ${ }^{26}$ Moreover one would expect that the influence would be selective; the diffusion of large molecules would be more restricted than the diffusion of small molecules.

There are two basic configurations to study such systems. In one, the gel network has a relatively small surface-to-volume ratio and the gel responds to $\mathrm{pH}$ homogeneously. In the other case, the gel network has an extended surface (high surface-to-volume ratio) and a local change in the $\mathrm{pH}$ causes a local change in the network structure in a patterned manner. 
The first configuration can be constructed from a small slab of $\mathrm{pH}$ sensitive hydrogel (PNIPA-PAAM) exposed to an appropriate oscillating chemical reaction. Since the PNIPA-PAAM system has the best response to $\mathrm{pH}$ between $\mathrm{pH}=4-7$, the ferrocyanide-iodate-sulfite (FIS) reaction is a good candidate, since it exhibits $\mathrm{pH}$ oscillations between 4 and 7.5 in a continuously stirred tank reactor (CSTR). ${ }^{1}$ The period of the oscillation in the FIS reaction is approximately $15-20 \min ^{30}$ As the reaction occurs, the hydrogel will respond to the $\mathrm{pH}$ oscillations and will change its size periodically. Furthermore, if one side of the gel is blocked in such a way that it remains flexible but would not allow significant diffusion, the expansion and contraction of the opposite side would result in a periodic swinging motion. To develop this idea further, a layered gel structure can be constructed in which two (or more) layers of gel are bound together. With tuning of the $\mathrm{pH}$ sensitivity of the individual gel layers, tailored mechanical responses can be obtained from the coupled gel system. The mechanical response of the gel system can be utilized in many ways. One could construct a "chemomechanical valve" that opens/closes a channel of reactant(s) depending on the $\mathrm{pH}$. Such a valve can be installed in a CSTR that has a chemical reaction system in it (e.g. the FIS reaction). This way the internal dynamics of the chemical system controls the reactant flow. This arrangement resembles a living organism that takes in 'food' when it needs it.

In the second type of configuration, the PNIPA-PAAM gel has spatially extended dimensions. The experimental arrangement can be seen in Figure 2.1. The reactants are fed from containers at high flow rates into the spatial reactor to provide turbulent flow and to make sure that the gel is always in contact with fresh solutions. Fresh stock 


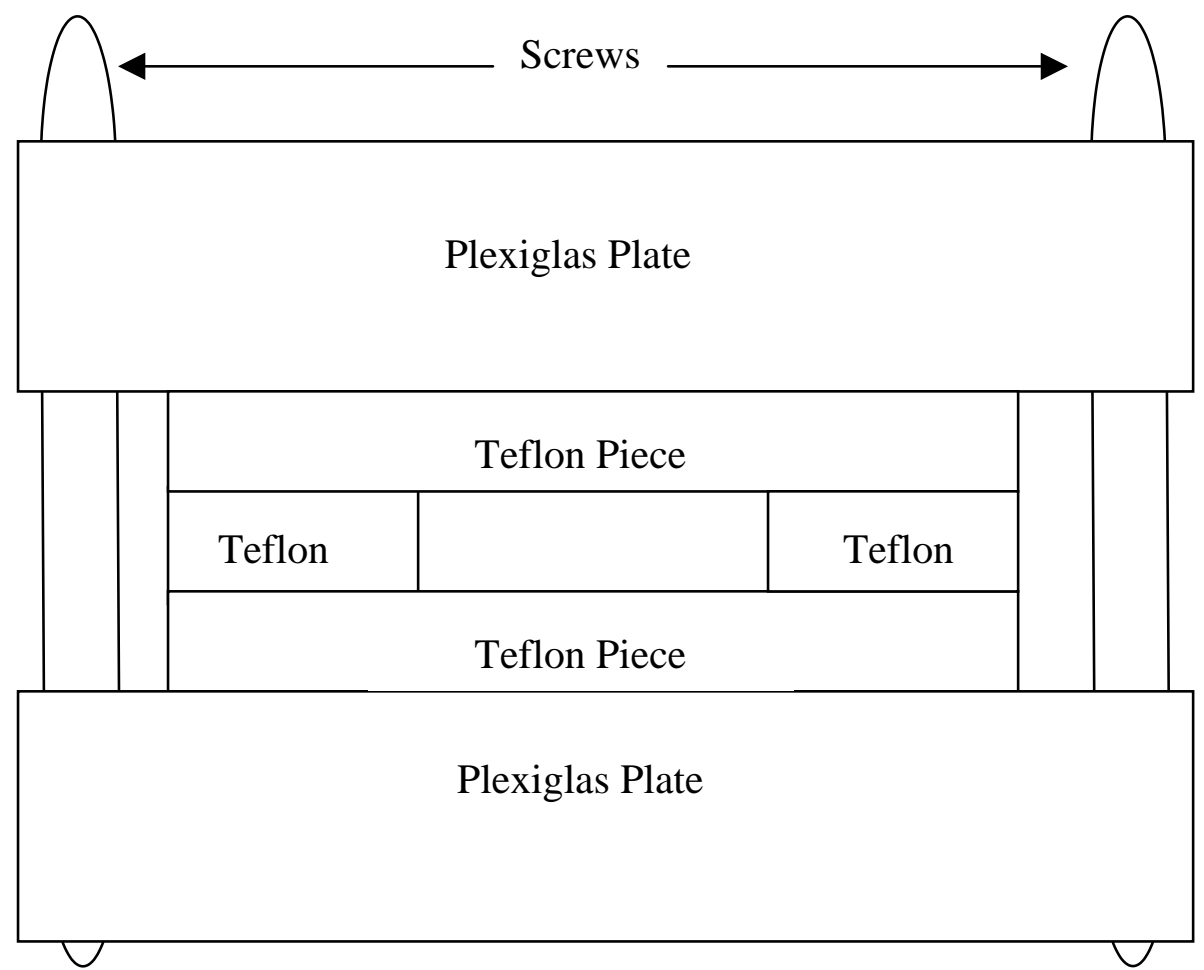

Figure 2.1. Apparatus for the Poly-isopropylacrylamide and Polyacrylamide coMethacrylic Acid Gels 
solution flows into these containers at very low flow rate. In the spatial reactor, the gel is held tightly between two Anopore and cellulose membranes. The membrane surfaces are exposed to a $3 \mathrm{~mm}$ layer of solution with turbulent flow. Considering again the FIS reaction, two solutions are made: one has sulfuric acid, potassium iodate, and bromothymol blue indicator, and the other has potassium ferrocyanide and sodium sulfite. The two solutions are fed into the spatial reactor from opposite sides. The solutions diffuse into the PNIPA-PAAM gel through the cellulose membrane and react in the gel network. This chemical system exhibits a variety of spatial structures and rich dynamical behavior in homogeneous gel medium. ${ }^{31}$ In our system, the patterns will locally change the $\mathrm{pH}$ in the gel, resulting in local collapsing and expansion of the matrix. Since the gel is restricted in space, the overall size and shape will not change. However, in the collapsed sections the diffusion rate will be significantly decreased compared to that in the expanded sections. Moreover the decrease in the diffusion rate in the collapsed section will probably be selective; bulky molecules (like the ferrocyanide) will be more influenced than the small ones (like sulfite). On the other hand, $\mathrm{H}^{+}$ions will be in dissociation equilibrium with the carboxylate group on the chain and therefore be partially immobilized. This deviation in diffusion properties will result in unpredictable influence on the spatial-dynamical behavior of the system. 


\subsection{Experimental}

\subsubsection{Solutions}

The stock solution concentrations are related to the concentrations in the CSTR by

$$
\mathrm{C}_{\circ}^{i}=\mathrm{C}_{s}^{i}\left(\frac{v_{i}}{v_{1}+v_{2}+v_{3}+v_{4}}\right)
$$

where $\mathrm{C}_{\mathrm{s}}{ }^{i}$ is the concentration of each species before reaching the CSTR, $\mathrm{C}_{\mathrm{o}}{ }^{i}$ is the desired concentration of each species in the CSTR, $v_{1}-v_{4}$ are the flow rates of each chamber, and $v_{\mathrm{i}}$ is the specific flow rate for the species being calculated.

All the solutions were made using chemicals from Fisher Scientific Co. and doubly distilled water. Stock solutions were prepared by either using the concentration determined from eq 2.1 or using another desired concentration and then multiplying by the molecular weight to obtain the mass of the desired chemical needed for a $1 \mathrm{~L}$ solution. For sulfuric acid, a $6 \mathrm{M}$ solution was prepared from the concentrated solution (18 M) from Fisher. Using the $6 \mathrm{M}$ solution, stock solutions were made by either dividing the concentration determined from eq 2.1 or dividing another desired concentration by $6 \mathrm{M}$ and multiplying by $1000 \mathrm{ml}$ to determine volume needed for a $1 \mathrm{~L}$ solution. Nitrogen gas was then bubbled into all the solutions for 1 hour, because of the air sensitivity of the reaction system. Table 2.1 gives the chemicals used. 
Table 2.1. Chemicals for the FIS Reaction

\begin{tabular}{|c|c|c|c|}
\hline Chemicals & Chemical Formula & Molecular Weight & Concentration \\
\hline $\begin{array}{c}\text { Potassium } \\
\text { Ferrocyanide }\end{array}$ & $\mathrm{K}_{4} \mathrm{Fe}(\mathrm{CN})_{6}$ & $422.41 \mathrm{~g} / \mathrm{mole}$ & $2.5 \times 10^{-2} \mathrm{M}$ \\
\hline Potassium Iodate & $\mathrm{KIO}_{3}$ & $214.01 \mathrm{~g} / \mathrm{mole}$ & $7.5 \times 10^{-2} \mathrm{M}$ \\
\hline Sodium Sulfite & $\mathrm{Na}_{2} \mathrm{SO}_{3}$ & $126.04 \mathrm{~g} / \mathrm{mole}$ & $8.93 \times 10^{-2} \mathrm{M}$ \\
\hline Sulfuric Acid & $\mathrm{H}_{2} \mathrm{SO}_{4}$ & $98.08 \mathrm{~g} / \mathrm{mole}$ & $3.5 \times 10^{-3} \mathrm{M}$ \\
\hline
\end{tabular}

\subsubsection{Gels}

\subsubsection{Polyacrylamide/Bis-acrylamide Co-acrylic Acid gel}

To prepare the polyacrylamide gel co-polymerized with acrylic acid, a gel solution is first prepared. Three grams of acrylamide (AA) is combined with $0.1 \mathrm{~g}$ bisacrylamide (cross-linker, BAA), both from Fisher, and $40.0 \mathrm{ml}$ of doubly distilled water. This solution is thoroughly mixed and $2.95 \mathrm{ml}$ of acrylic acid (AAc) from Fisher is then added. Three different size gels were made. For each gel, N,N,N',N'tetramethylethylenediamine (TEMED), from Aldrich, was used as a chain carrier and $10 \%$ ammonium persulfate (AP) was used as an initiator. To make $10 \%$ ammonium persulfate, $2.00 \mathrm{~g}$ of ammonium peroxydisulfate, from Fisher, was dissolved in $20.0 \mathrm{ml}$ of doubly distilled water. For the smaller gels, a detergent was used to break the surface tension of the water. The gels and corresponding volumes of reagents used are listed in Table 2.2. 
Table 2.2. Gel Preparations

\begin{tabular}{|l|l|l|}
\hline \multicolumn{1}{|c|}{ Gel Solution } & \multicolumn{1}{|c|}{ TEMED } & \multicolumn{1}{c|}{ AP } \\
\hline $12 \mathrm{ml}$ & $500 \mu \mathrm{l}$ & $2 \mathrm{ml}$ \\
\hline $6 \mathrm{ml}+4$ drops detergent & $400 \mu \mathrm{l}$ & $1.25 \mathrm{ml}$ \\
\hline $2 \mathrm{ml}+10$ drops detergent & $134 \mu \mathrm{l}$ & $0.4 \mathrm{ml}$ \\
\hline
\end{tabular}

The gel solution was boiled in a $50 \mathrm{ml}$ beaker and detergent was then added (or not). The TEMED and AP were then quickly added and the solution was quickly poured into a petri dish and covered. The gelling process lasted approximately 10 minutes and the gels were then rinsed to remove any unreacted chemicals and soaked in doubly distilled water overnight to swell the gel. The petri dish used for the first two gels listed in the table was a $100 \times 15 \mathrm{~mm}$ Plexiglas petri dish and a 60 x $15 \mathrm{~mm}$ Plexiglas petri dish was used for the last one.

\subsubsection{Polyacrylamide/Bis-acrylamide Gel}

A 40\% (w/w) solution of polyacrylamide/bis-acrylamide gel solution, from Aldrich Chemical Co., was diluted to $10 \%$ (w/w). To make the gel, $12.0 \mathrm{ml}$ of the $10 \%$ (w/w) solution was boiled and to it was quickly added $200 \mu \mathrm{l}$ TEMED and $600 \mu \mathrm{AP}$, in that order. The gel was then quickly poured into a $100 \times 15 \mathrm{~mm}$ Plexiglas petri dish and covered. In approximately 10 minutes, the gel was ready to use. 


\subsubsection{Poly-isopropylacrylamide Gel}

To make this gel, $0.156 \mathrm{~g}$ of $\mathrm{N}$-isopropylacrylamide (IPAAm, monomer), $4.0 \mathrm{mg}$ of N,N-methylenebis(acrylamide) (MBA, cross-linker), and $6.6 \mathrm{mg}$ of $\mathrm{N}, \mathrm{N}-$ azobis(isobutyronitrile) (ABIBN, initiator), all from Aldrich, were dissolved in $1.0 \mathrm{ml}$ of methanol (previously purged with $\mathrm{N}_{2}$ gas). The solution was injected into a mold consisting of three Teflon pieces. One of the pieces is a spacer to form a chamber where the solution was injected and the gel formed. Two different spacers were used, depending on the size gel needed. One is $1.0 \mathrm{~mm}$ thick and the other is $3.0 \mathrm{~mm}$ thick. The mold was secured between two Plexiglas blocks and tightened securely with screws (see Figure 2.1). The apparatus was placed in a $60^{\circ} \mathrm{C}$ water bath for 18 hours. The gel was then immersed in methanol for one week, changing the methanol daily, to remove unreacted compounds. The gel was then soaked in $75 / 25 \%(\mathrm{v} / \mathrm{v}), 50 / 50 \%(\mathrm{v} / \mathrm{v})$, and 25/75\% (v/v) of methanol/water for one day at each concentration. After the gel was soaked in doubly distilled water for one day, it was then ready for use.

\subsubsection{Poly-isopropylacrylamide co-Methacrylic Acid Gel}

To make this gel, $4.4 \mathrm{~g}$ of IPAAm, $0.6 \mathrm{~g}$ of methacrylic acid (MAA, copolymer), from Aldrich, $0.1 \mathrm{~g}$ ethylene glycol dimethacrylate (EGDMA, cross-linker), from Aldrich, and $0.05 \mathrm{~g} \mathrm{ABIBN}$ with $5.0 \mathrm{ml}$ of 50/50\% (v/v) methanol/water were mixed. Nitrogen gas was then bubbled into the solution for 5 minutes. The solution was injected into the mold (see Figure 2.1) and placed in a $50^{\circ} \mathrm{C}$ water bath for 24 hours. The gel was then ready for use. 


\subsubsection{Polyacrylamide/Bis-Acrylamide Co-Acrylic Acid Two Layer Gel}

Binding two gels together yields this two layer gel. The first layer consists of 4.0 $\mathrm{ml}$ of gel solution (see section 2.2.2.1) and $5.0 \mathrm{mg}$ of bis-acrylamide mixed together and boiled. To this was quickly added $0.3 \mathrm{ml}$ of TEMED and $1.7 \mathrm{ml} \mathrm{AP}$, in this order, and the solution was placed in a $60 \times 15 \mathrm{~mm}$ Plexiglas petri dish. This first layer was allowed to completely gel. The second layer consisting of $4.0 \mathrm{ml}$ gel solution (see section 2.2.2.1), $5.0 \mathrm{mg}$ bis-acrylamide, and $12.0 \mathrm{mg} \operatorname{Bis}(2,2$ '-bipyridyl)-(4-methyl-4'vinylbipyridyl)-ruthenium(II) $\left(\mathrm{Ru}(\mathrm{bpy})_{2}(\mathrm{vpy})\right)$ was mixed together and boiled. To this was quickly added $0.3 \mathrm{ml}$ of TEMED and $1.7 \mathrm{ml} \mathrm{AP}$, in this order, and this solution was poured on top of the first gel. After 10 minutes, the second gel was bound to the first and the composite gel was soaked in doubly distilled water.

\subsubsection{Reaction Set-ups}

\subsubsection{Continuous Flow Stirred Tank Reactor}

The continuous flow stirred tank reactor (CSTR) consists of a glass cylinder container fitted with a water jacket with inlet and outlet flow for temperature control. A Fisher Scientific Isotem Refrigerated Circulator controlled the temperature. The top of the CSTR was covered with a Teflon cap with holes drilled for chemical inflow and outflow and a hole for $\mathrm{pH}$ measurements. Four tubes were connected to the CSTR from the Gilson Minipuls3 peristaltic pump, pumping in potassium ferrocyanide, potassium iodate, sodium sulfite, and sulfuric acid solutions. The outflow tube, connected to an aspirator, maintained a constant volume of $60 \mathrm{ml}$. The final hole was fitted for an Orion 


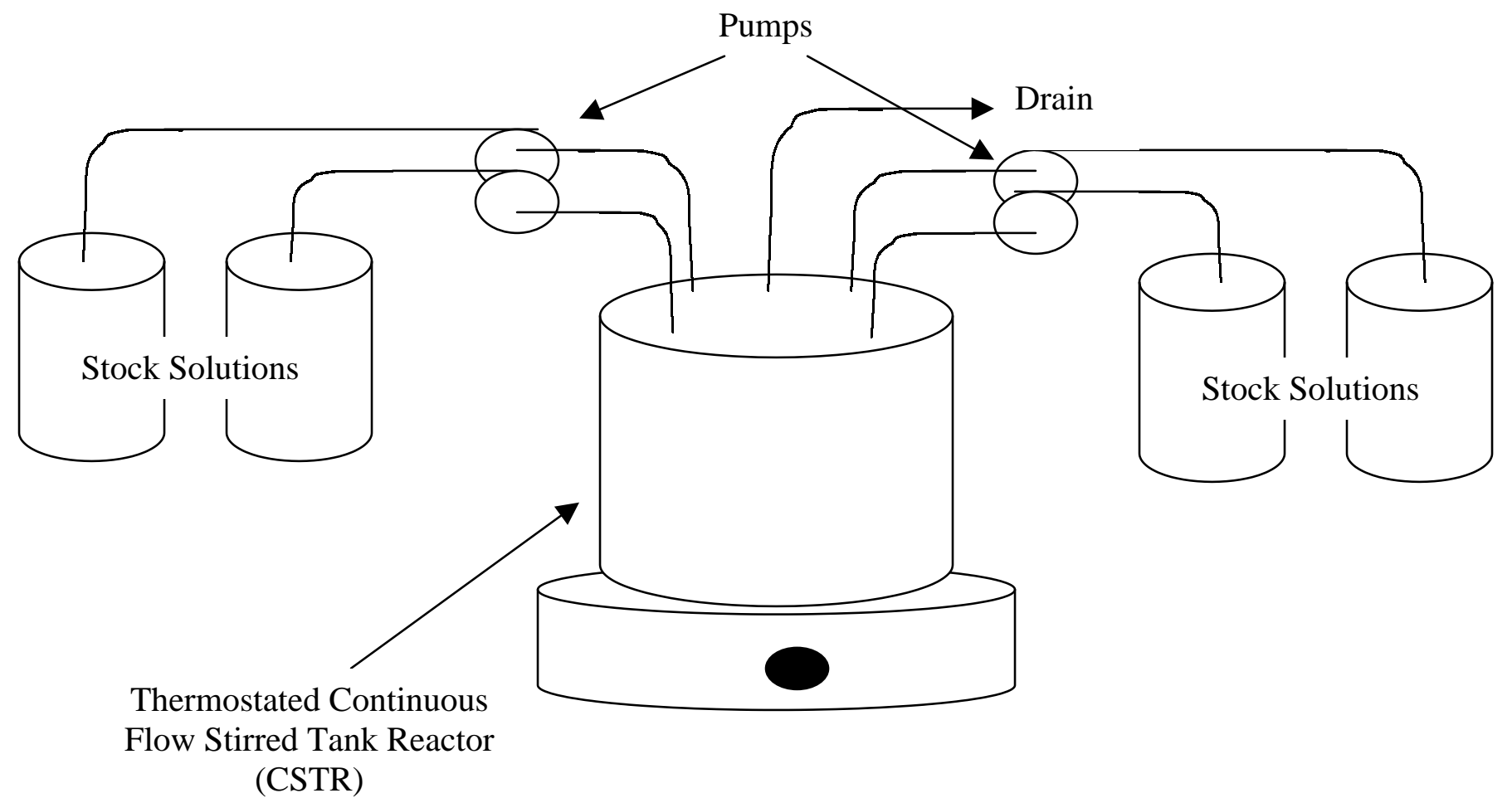

Figure 2.2. Reaction Set-up for CSTR 
pH electrode, connected to an Orion Expandable Ion Analyzer EA 940. The solution was mixed by a magnetic stir bar. See Figure 2.2 for set-up.

\subsubsection{Spatial Pattern Studies}

The two reactant solutions were fed into the spatial reactor from opposite sides. The solutions diffuse into the PNIPA-PAAM gel through the cellulose membrane and react in the gel network. A camera attached to a computer is used to observe the spatial patterns that develop in the gel. An Oriel tungsten-halogen lamp was used to illuminate the system. The spatial reactor and stirred containers are kept at a constant temperature using a MGW Lauda C20 thermostated water bath. Figure 2.3 shows the reaction set-up for this experiment.

\subsubsection{Experiments}

\subsubsection{FIS Oscillatory Experiments in a CSTR}

The peristaltic pump has four flow chambers with each chemical pumped from $1.0 \mathrm{~L}$ bottles into the CSTR (see Figure 2.2). In all experiments, $2.79 \mathrm{~mm}$ I.D. tygon tubing was used. The flow rates were varied to study the effects on the oscillations. The desired concentrations inside the CSTR are given in Table 2.1. To determine the concentrations of the stock solutions, eq 2.1 is used after determining the flow rates of each chamber. Due to fluctuations in the flow rate, the rates are calculated every two days to ensure the concentrations are accurate. Each flow rate is measured as the time (in seconds) for 10 
$\mathrm{ml}$ of water to fill a container. Chemicals flow into the reactor and $\mathrm{pH}$ measurements are taken and recorded using a chart recorder attached to the $\mathrm{pH}$ meter.

\subsubsection{Spatial Pattern Studies}

Knowing the $\mathrm{pH}$ oscillatory behavior of the FIS reaction, the study of spatiotemporal patterns on an acrylamide/co-acrylic acid gel was performed. In this

project, the FIS reaction takes place inside the gel, using the spatial reactor.

Bromothymol blue indicator can be used to detect the $\mathrm{pH}$ changes occuring in the gel. The results of this experiment will show patterns of high (yellow color) and low (blue color) $\mathrm{pH}$ as the reaction oscillates.

\subsection{Results}

\subsubsection{FIS Oscillatory Experiments in a CSTR}

The set-up for this experiment is shown in Figure 2.2. The flow rate for each of four flow chambers was determined by measuring the time (seconds) it takes to fill $10 \mathrm{ml}$. After the flow rates were determined, the stock solution concentrations are determined using eq 2.1 (see Table 2.3). 
$\mathbf{A}$

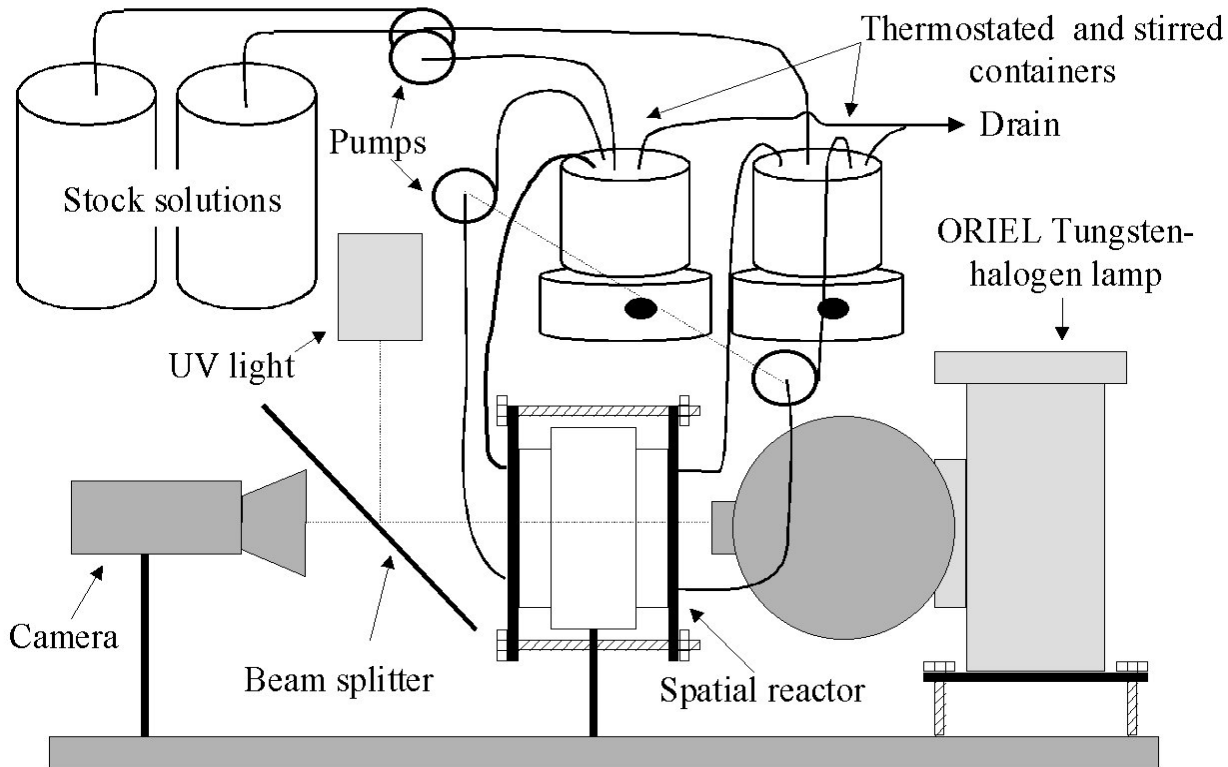

$\mathbf{B}$

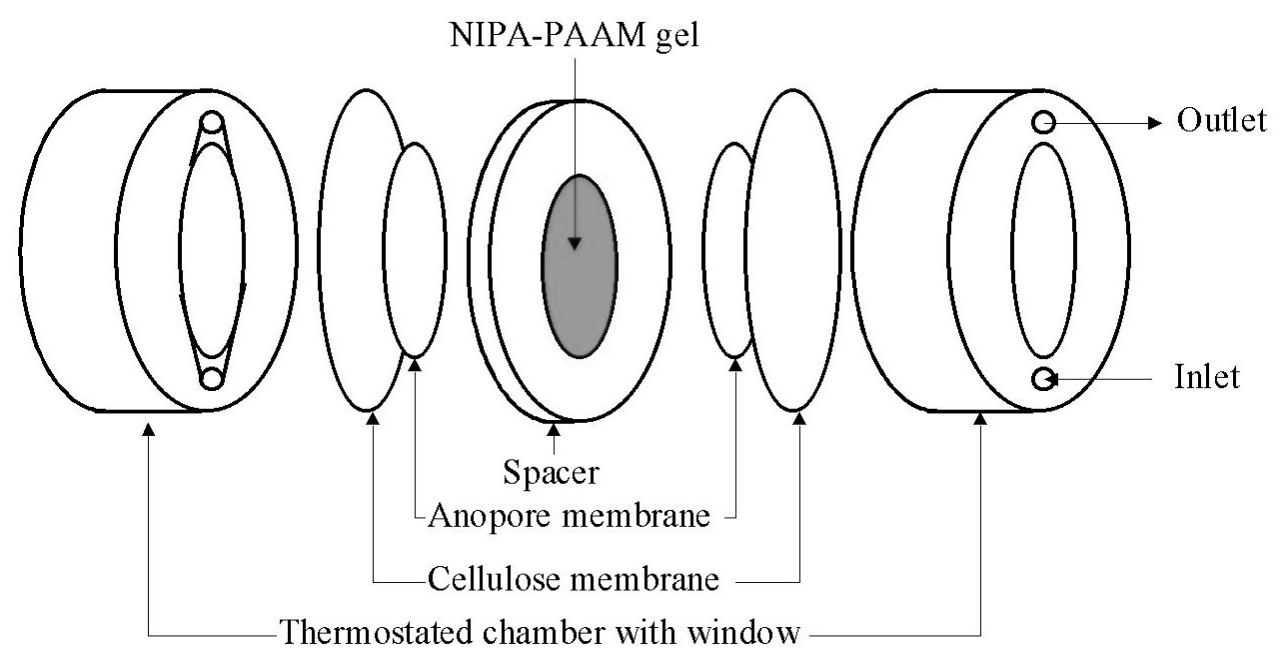

Figure 2.3. Reactor Set-up for Spatial Pattern Studies. A) Reaction Set-up. B) Reactor housing gel. 
Table 2.3. Flow Rates and Concentrations

\begin{tabular}{|c|c|c|c|}
\hline Chemicals & $\mathbf{C}_{\mathbf{o}}{ }^{\boldsymbol{i}}(\mathbf{M})^{\mathbf{a}}$ & $\boldsymbol{v}_{\boldsymbol{i}}(\mathbf{m l} / \mathbf{s})^{\mathbf{b}}$ & $\mathbf{C}_{\mathbf{s}}{ }^{\boldsymbol{i}}(\mathbf{M})^{\mathbf{c}}$ \\
\hline $\mathrm{KIO}_{3}$ & $7.5 \times 10^{-2}$ & 0.1318 & $3.5 \times 10^{-1}$ \\
\hline $\mathrm{K}_{4} \mathrm{Fe}(\mathrm{CN})_{6}$ & $2.5 \times 10^{-2}$ & 0.1519 & $1.0 \times 10^{-1}$ \\
\hline $\mathrm{Na}_{2} \mathrm{SO}_{3}$ & $8.93 \times 10^{-2}$ & 0.1689 & $3.21 \times 10^{-1}$ \\
\hline $\mathrm{H}_{2} \mathrm{SO}_{4}$ & $3.5 \times 10^{-3}$ & 0.1549 & $1.4 \times 10^{-2}$ \\
\hline
\end{tabular}

a. $\mathrm{C}_{\mathrm{o}}{ }^{i}=$ concentration of species $i$ in reactor

b. $v_{i}=$ Flow rate of species $i$

c. $\mathrm{C}_{\mathrm{s}}{ }^{i}=$ concentration of species $i$ in reactant reservoir

The $\mathrm{pH}$ changes over a wide range of flow rates were measured. The $\mathrm{pH}$ meter was connected to a chart recorder, which recorded the oscillations. Starting at a flow rate of $2.5 \times 10^{-3} \mathrm{~s}^{-1}$, the system oscillated in a $\mathrm{pH}$ range of 7.26 to 3.86 . If the flow rate was increased, no oscillations occurred and the $\mathrm{pH}$ range fluctuated between 7 and 8 . If the flow rate was lowered, oscillations were still prevelant, although at a slower rate. These results can be seen in Table 2.3. As the flow rates decrease, the $\mathrm{pH}$ range becomes narrower. This behavior is due to the system changing to a state where the flow rate is low enough to exhibit behavior in the lower $\mathrm{pH}$ limit. Thus, the behavior of the system is such that it changes from higher $\mathrm{pH}$ limits at higher flow rates, to oscillatory behavior, to lower $\mathrm{pH}$ limits at lower flow rates. Figure 2.4 shows the results of oscillations recorded at a flow rate of $2.25 \times 10^{-3} \mathrm{~s}^{-1}$, and Figure 2.5 shows results from earlier work. ${ }^{3}$ The flow rate in Figure 2.5 is $2.5 \times 10^{-3} \mathrm{~s}^{-1} .^{3}$ 
Table 2.4. Flow Rates and pH Ranges

\begin{tabular}{|c|c|c|}
\hline Peristaltic Pump Setting & Flow Rate $\left(\mathbf{s}^{-\mathbf{1}}\right)$ & pH Range \\
\hline 5.00 & $2.5 \times 10^{-3}$ & $7.26-3.86$ \\
\hline 4.50 & $2.25 \times 10^{-3}$ & $7.20-3.62$ \\
\hline 4.00 & $2.00 \times 10^{-3}$ & $7.16-3.81$ \\
\hline 3.50 & $1.75 \times 10^{-3}$ & $6.97-3.65$ \\
\hline 2.50 & $1.25 \times 10^{-3}$ & $6.90-3.63$ \\
\hline 2.00 & $1.00 \times 10^{-3}$ & $6.80-4.02$ \\
\hline 1.50 & $0.75 \times 10^{-3}$ & $6.71-3.74$ \\
\hline 1.00 & $0.50 \times 10^{-3}$ & $6.60-4.12$ \\
\hline 0.50 & $0.25 \times 10^{-3}$ & $6.32-4.01$ \\
\hline 0.25 & $1.25 \times 10^{-4}$ & \\
\hline
\end{tabular}




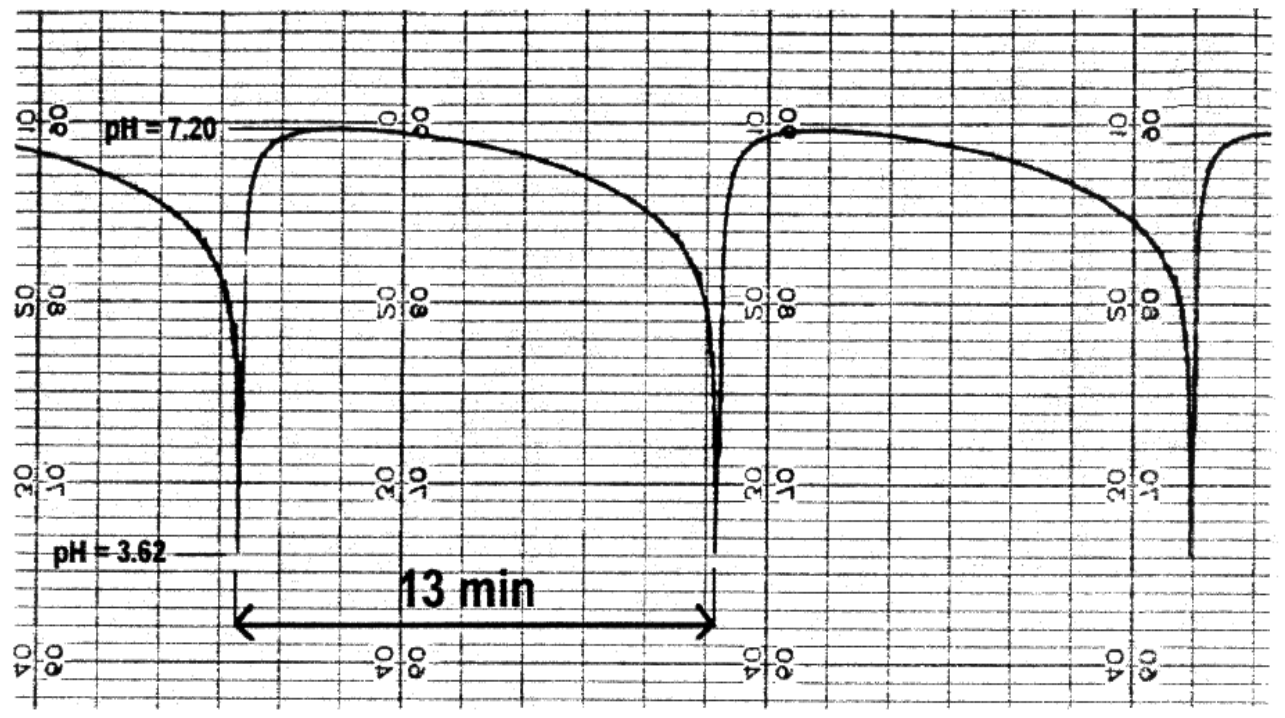

Figure 2.4. $\mathrm{pH}$ oscillations in the FIS reaction with flow rate of $2.25 \times 10^{-3} \mathrm{~s}^{-1}$ and temperature of $40^{\circ} \mathrm{C}$. 


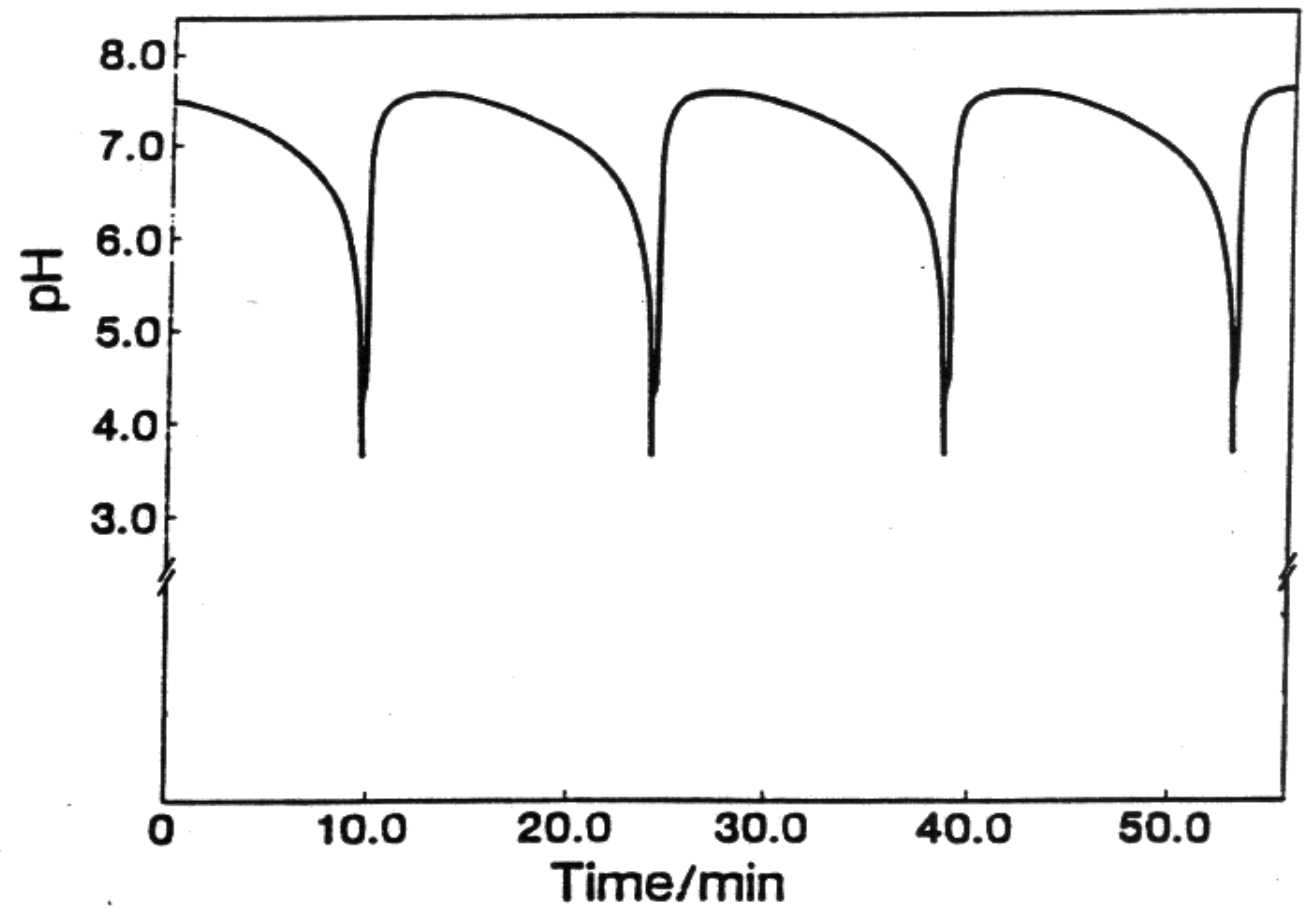

Figure 2.5. $\mathrm{pH}$ oscillations in the FIS reaction with flow rate of $2.5 \times 10^{-3} \mathrm{~s}^{-1}$ and temperature of $40^{\circ} \mathrm{C}$. Figure from Ref 3 . 


\subsubsection{Spatial Pattern Studies}

Table 2.5 shows the concentrations used and the results corresponding to these concentrations. A major problem was large concentrations of iodine present that crystalized on the gel and did not permit any $\mathrm{pH}$ patterns to be distinquished. One solution to this problem was to change the concentration of the solutions to allow $\mathrm{pH}$ oscillations without iodine crystalization. Another problem in this experiment involved the gel shrinking inside the reactor so that the reaction no longer took place in the gel. This problem was solved by first soaking the gel in a solution of sulfuric acid (4.0 mM) before cutting it into size and placing in the reactor.

Table 2.5. Results of Spatial Pattern Experiments

\begin{tabular}{|c|c|c|c|c|c|}
\hline \multicolumn{5}{|c|}{ Stock Solution Concentrations (M) } & \multirow{3}{*}{ Results } \\
\hline \multicolumn{3}{|c|}{ Solution A } & \multicolumn{2}{|c|}{ Solution B } & \\
\hline $\mathrm{H}_{2} \mathrm{SO}_{4}$ & $\mathrm{KIO}_{3}$ & $\begin{array}{l}\text { Bromothymol } \\
\text { blue }\end{array}$ & $\mathrm{Na}_{2} \mathrm{SO}_{3}$ & $\mathrm{~K}_{4} \mathrm{Fe}(\mathrm{CN})_{6}$ & \\
\hline 0.0072 & 0.150 & $1.28 \times 10^{-5}$ & 0.089 & 0.0284 & $\begin{array}{c}\text { Initially saw } \\
\text { patterns } \\
\text { forming, but } \\
\text { iodine crystals } \\
\text { began to form. }\end{array}$ \\
\hline 0.0072 & 0.150 & $1.28 \times 10^{-5}$ & 0.089 & 0.0568 & $\begin{array}{c}\text { Same results as } \\
\text { above. }\end{array}$ \\
\hline 0.0072 & 0.075 & $1.28 \times 10^{-5}$ & 0.178 & 0.1136 & $\begin{array}{c}\text { Same results as } \\
\text { above. }\end{array}$ \\
\hline 0.0144 & 0.300 & $2.6 \times 10^{-5}$ & 0.356 & 0.0568 & $\begin{array}{c}\text { Same results as } \\
\text { above. }\end{array}$ \\
\hline
\end{tabular}




\subsection{Discussion}

Another project utilizing the properties of the FIS reaction was to monitor the effects of oscillating $\mathrm{pH}$ on gels. Two examples of gels that exhibit swelling and deswelling upon changes in $\mathrm{pH}$ in the range of the FIS reaction are polyisopropylacrylamide gel $^{32}$ and poly-isopropylacrylamide co-methacrylic acid ${ }^{26}$ gel. These gels have shown changes in size by ten-fold as $\mathrm{pH}$ changes from 7 to 4 . One problem that needs to be addressed is the time needed for the gel to fully respond to the $\mathrm{pH}$ changes. In the FIS reaction, slowing down the flow rate and lowering the temperature yields a longer period of oscillation. However, the majority of the time of the oscillation is spent in the upper $\mathrm{pH}$ range. At this $\mathrm{pH}$, the gel has deswelled and needs longer times to reswell. For this reason, the second gel listed above would be a good choice, because it swells at higher $\mathrm{pH}$ and deswells at lower $\mathrm{pH}$. 


\section{Chapter 3}

\section{Light Sensitive Behavior}

\subsection{Purpose}

If the PNIPA backbone network is modified with a 'ligand' that has multiple redox potentials instead of a chain that is $\mathrm{pH}$ sensitive, the constructed polymer network will uniquely respond to the changing of the redox potential of the environment. The obvious candidates are complex compounds with a metal center, like rutheniumbipyridyl, $\mathrm{Ru}(\mathrm{bpy})_{3}{ }^{2+}$, one of the catalysts of the $\mathrm{BZ}$ reaction. This molecule, however, must be modified in such a way that it can form a covalent bond with the gel matrix. ${ }^{32,33}$ We replaced one of the bipyridyl ligands in the $\mathrm{Ru}(\mathrm{bpy})_{3}{ }^{2+}$ complex with 4-methyl - 4'vinyl-2,2'-bipyridyl (vpy) that was synthesized in our laboratory with an improved method of Spiro et al. ${ }^{34}$ The product, Ru(vpy)(bpy) ${ }_{2}{ }^{2+}$, was then co-polymerized with NIPA (see Figure 3.1 for ruthenium complex structures). The resulting gel can then be placed into a BZ solution. Depending on the geometrical arrangements, this configuration reproduces the same effects through swelling and collapsing that were discussed above. In a spatially extended system, a wave of $\mathrm{Ru}(\mathrm{II}) / \mathrm{Ru}(\mathrm{III})$ can be initiated. As a result, a wave of expansion propagates through the gel.

The PNIPA-co-Ru(vpy)(bpy) 2 co-polymer transforms the chemical energy of the $\mathrm{BZ}$ reaction into chemomechanical work. The volume effect, however, is significantly less than in the case of the $\mathrm{pH}$ sensitive hydrogel. ${ }^{32}$ The redox state changes of the ruthenium seem to have significantly less influence on the overall structure of the gel 


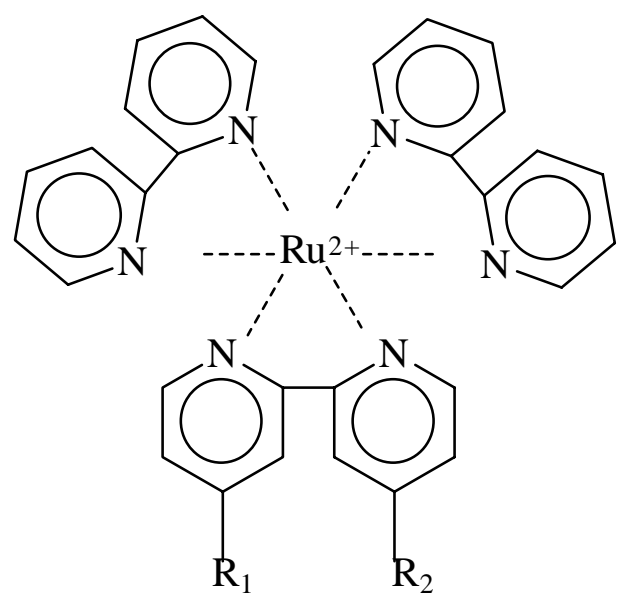

Figure 3.1. Structure of the ruthenium complex, $R u(b p y)_{3}: R_{1}=R_{2}=H$; $R u(v p y)(b p y)_{2}$ : $\mathrm{R}_{1}=\mathrm{CH}_{3}, \mathrm{R}_{2}=$ (vinyl). 
matrix. To improve the response of the gel we must develop ligands that have a more pronounced response to a change in the redox state of ruthenium. We are investigating possibilities where the $\mathrm{Ru}(\mathrm{II}) / \mathrm{Ru}(\mathrm{III})$ change triggers a reorganization of the polymer network.

One experiment utilizing the photosensitive behavior of the $\mathrm{BZ}$ reaction is the study by Kádár et al. of stochastic resonance. ${ }^{33}$ The phenomenon of stochastic resonance is the use of noise to improve the detection of weak signals of nonlinear dynamical systems in noisy environments. In adding noise to the system, there is a threshold at which the system is overwhelmed by noise and the signal is no longer improved. "Studies of stochastic resonance and noise effects in biological and excitable dynamical systems have attracted particular interest, because of the possibility of noise-supported signal transmission in neuronal tissue and other excitable biological media."33 Kádár et al. studied the positive influences of noise on wave propagation in the BZ reaction. Their experiment consisted of an array of cells in which the light intensity of the cells was randomly varied. As the noise level increased, wave propagation was enhanced until reaching a point at which the system was overwhelmed by the noise (noise level maximum) and the waves fragmented (see Figure 3.2).

Another experiment utilizing the photosensitivity of the BZ system is the study of self-organized criticality (SOC). Many large interactive systems naturally organize into a critical state, as a result of accumulating perturbations in which a minor perturbation can cause an "avalanche". After the "avalanche", the systems naturally reorganize into a new critical state. This is the theory of SOC proposed by Bak et al. ${ }^{35}$ 


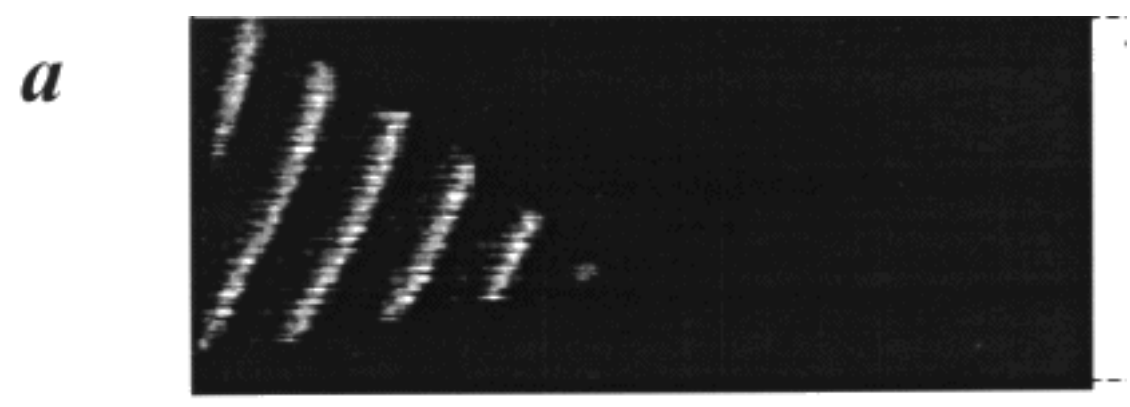

$\boldsymbol{b}$

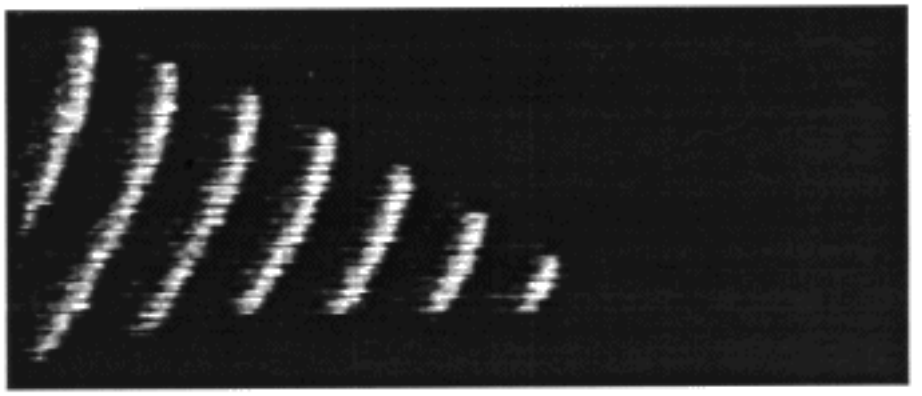

c
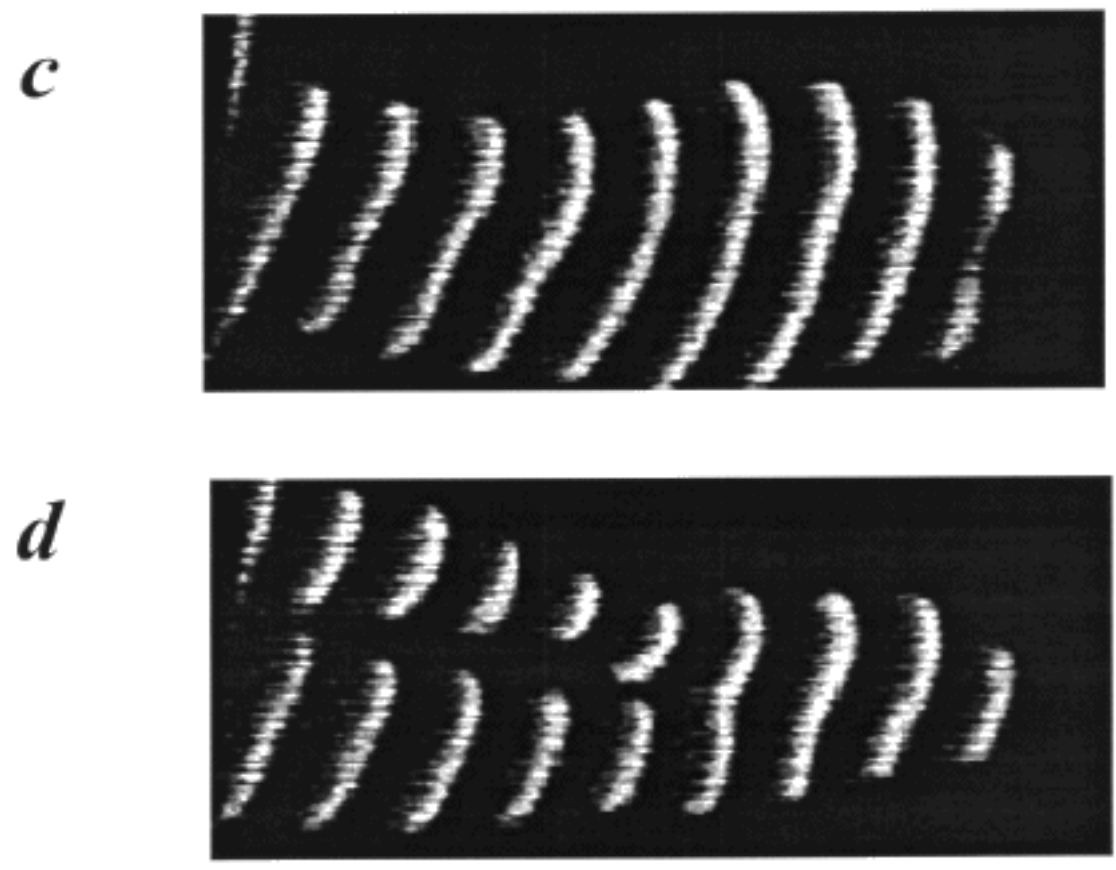

Figure 3.2. Image sequences showing influence of noise on wave propagation. Images of wave segments travelling through the BZ medium perturbed by a) 0, b) 0.3 , c) 0.6 , and d) 1.0 of the maximum noise level permitted by the experiment. Figure from Ref 36 . 
To exhibit SOC behavior, a system must display two characteristics. One is the above behavior of self-organizing into a critical state. The other is that the system must follow a power law. This power law shows that there is a probability of "avalanches" of all sizes occurring. The specifics of the "avalanche" depend on the system. This graph of the power law is compared to that for $1 / \mathrm{f}$ noise and follows eq 3.1 , where $1 /$ f noise reflects the intrinsic dynamics of the SOC system. ${ }^{37}$

$$
S(f) \approx f^{-\beta}
$$

There are many examples of systems exhibiting SOC behavior. One is the work of Zanette et al. ${ }^{38}$ in their study of city and urban populations aimed at understanding the growth and decline of city populations. Their reaction/diffusion model shows the distribution of populated areas around the world. The reaction process of this model is a stochastic multiplicative process that states that the increase in population in a certain area depends upon the population itself and is controlled by a parameter known as the reaction probability. The diffusion process is representative of the natural movement of people from highly populated areas to less densely populated areas and is controlled by a parameter describing the fraction of population leaving an area at a given time. This model exhibits the power law given in eq 3.2, where $f(n)$ is the number of cities with $n$ inhabitants and $\alpha$ is close to 2 .

$$
\mathrm{f}(\mathrm{n}) \propto \mathrm{n}^{-\alpha}
$$

Another example of SOC behavior is the work of Jung and the study of noisesustained thermal patterns. ${ }^{39}$ His model consists of a square array of excitable threshold elements. These elements can be in three states, quiescent, excited, and refractory. The 
state of an element depends upon the input. If the input is below threshold, the state is quiescent. It switches to excited at the point the input crosses the threshold. After which, the element fires, gives off accumulated thermal energy to its surrounding elements and returns to the refractory state. The surrounding elements in the quiescent state begin to fire as well. The firing elements are arranged in clusters whose size depends upon the number of surrounding elements in the excited state at the point of firing. This model exhibits a power law similar to that described above,

$$
\mathrm{p}(\mathrm{s}) \propto \mathrm{s}^{-\alpha}
$$

where $\mathrm{p}(\mathrm{s})$ is the probability of a cluster of a certain size, $\mathrm{s}$, (in space and time) and $\alpha$ being equal to 2 (see eq 3.3).

One of the simplest models exhibiting SOC behavior is the sand pile model. In this model, sand is poured onto a flat surface which forms a pile. Initially, the system is in a subcritical state. As the sand grains are added, one grain at a time, the sand pile grows until reaching a critical state. When further perturbations (sand grains) are added to the system, the sand falls down the side of the pile creating an avalanche. The size of the avalanche depends upon the number of grains in the path of the falling sand that are unstable. The sand continues to fall until reaching a stable point. At this time a subcritical state has formed. The size of the avalanche and the time of occurrence are characterized by a power law. The power law correlation for this model is $\log [P(N)]$ vs. $\log (\mathrm{N})$, which is the probability that $\mathrm{N}$ grains will be in an avalanche as a function of $\mathrm{N}$ grains in the avalanche.

A final example is the earthquake model. "...if earthquakes are the natural consequences of the stationary dynamical state of the crust submitted to steady increasing 
stresses, they also organize the crust in a self-consistent way."40 When the crust layer is stressed strongly enough to cause deformation beyond a certain limit, rupture occurs and an earthquake follows. At this point, the crust plate rebounds because of the release of energy and this energy is radiated in the form of seismic waves. Earthquakes are very complex events involving stresses of the earth's crust. There is a power law distribution of these stresses predicted by past experiences and justified by actual occurrences. These power laws enable seismologist to determine the probability of earthquakes of different sizes. According to Sornette et al., ${ }^{40}$ earthquakes are a consequence of the organization of the crust and its array of faults and that the structure of the crust depends upon previous earthquakes.

The model for earthquakes is the first example of SOC to be demonstrated in a deterministic continuum dynamical system. ${ }^{41}$ The model consists of two plates simulating the earth's crust and its array of faults. There is the rigid plate (the earth's crust) and the elastic plate (array of faults) consisting of an array of blocks connected to four neighboring blocks by springs (see Figure 3.3 for a diagram of the elastic plate). Perturbations (spring force) are added randomly to the blocks at random times. This spring force adds up until reaching a critical state. At the critical state, further additions of force will cause sliding of the blocks, representing earthquakes. As the blocks slide, the force is released into neighboring blocks. If the neighboring blocks are at the critical value, they will begin to slide as well. The size of the earthquake depends on the number of neighboring blocks in the critical state. When the blocks slide, they are in the supercritical state and continue to slide until the spring force has been reduced to below the critical value, thus establishing a new critical state. ${ }^{36}$ The power law correlation for 


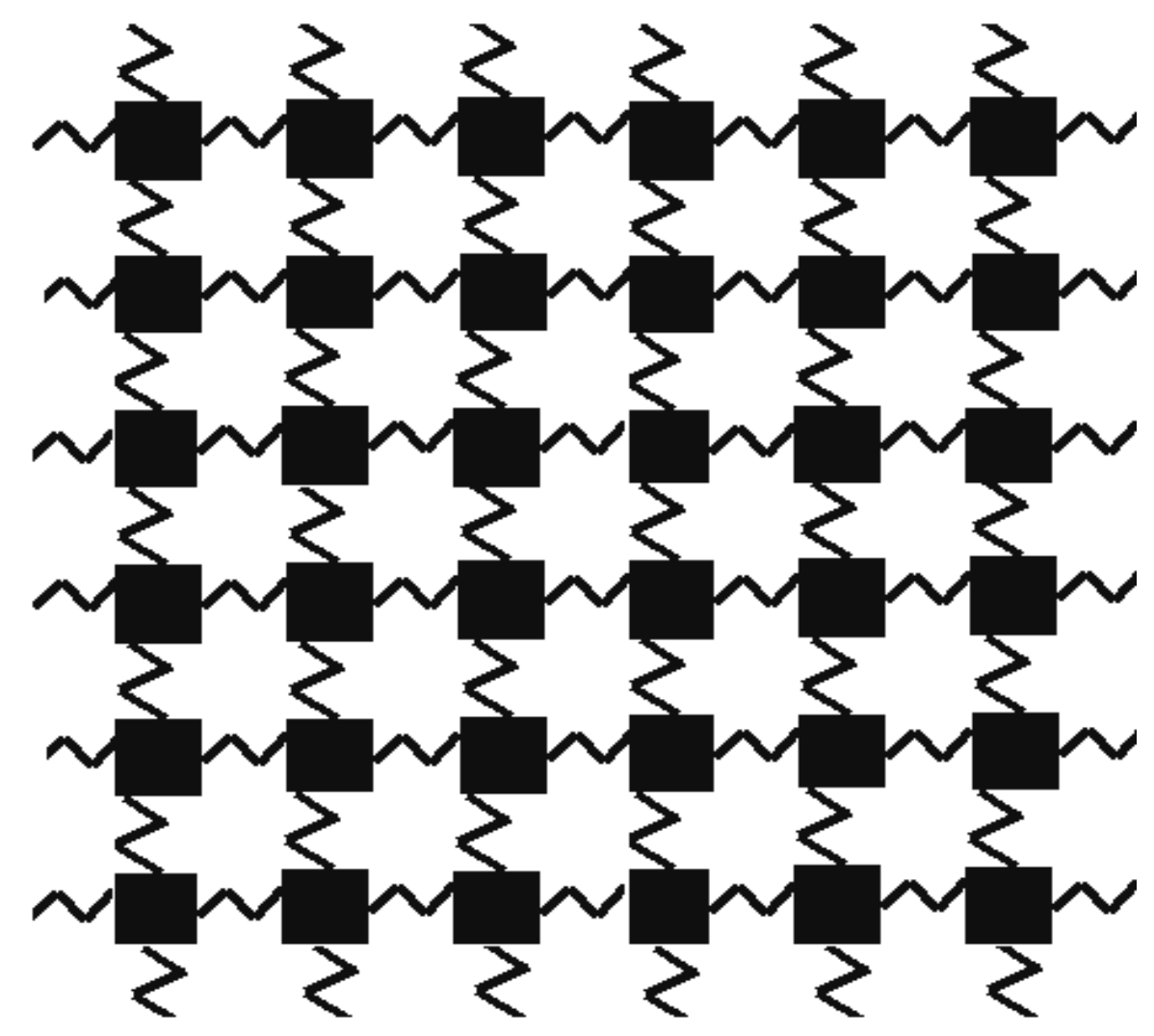

Figure 3.3. An array of blocks connected by springs simulating the elastic plate in the earthquake model. 
this model is $\log [\mathrm{P}[\mathrm{N}(\mathrm{E})]]$ vs. $\log (\mathrm{E})$, which describes the probability of a number of earthquakes with energy $E$ as a function of that energy. This is the energy exerted by the spring force. This power law reflects the fact that earthquakes of all sizes may occur. Another example of experiments utilizing the light sensitive behavior of the BZ system is periodic forcing. In periodic forcing, waves are sustained in a subexcitable medium not by noise patterns, but by changing the medium between just above the excitability limit and just below it. The excitability limit is established for the system and the amplitude for the change in light intensity is fixed at a few percent above and below the excitability limit. Positive perturbations allow wave propagation and negative perturbations hinder wave propagation.

Free end waves propagating into the medium slightly below the excitability limit begin to shrink at each end. If the medium is lowered below the excitability limit, the waves shrink at each end at a faster pace. The size the waves shrink to depends upon the amount of time spent in this medium. When the medium is raised above the excitability limit, the wave begins to grow. The growth is not only along the ends, but along the wave front also and so the wave begins to curve. The size of the wave depends upon both the size of the curvature and the time spent in this medium. Changing the medium to above the excitability has a greater effect upon the wave size than changing it below the excitability limit. The wave activity is therefore sustained. 


\subsection{Experiments}

\subsubsection{Gel}

A silica gel, with a thickness of $0.3 \mathrm{~mm}$, was prepared by mixing $0.667 \mathrm{ml}$ of $15 \%$ (w/w) $\mathrm{SiO}_{2}$ in water, $0.150 \mathrm{ml} \mathrm{Ru}(\mathrm{bpy})_{3}, 0.05 \mathrm{ml}$ doubly distilled water, and $0.080 \mathrm{ml}$ of 2.0 $\mathrm{M} \mathrm{H}_{2} \mathrm{SO}_{4}$. This gel was pipetted onto a Plexiglas plate and covered with a microscope slide as shown in Figure 3.4.

\subsubsection{Solutions}

The solutions were made using chemicals from Fisher and diluted to $1.0 \mathrm{~L}$ using doubly distilled water. Stock solutions were prepared by using the desired concentration and then multiplying by the molecular weight to obtain the mass of the desired chemical needed for a 1.0 L solution. For sulfuric acid, a 6.0 M solution was made from the original concentrated $(18.0 \mathrm{M})$ sulfuric acid from Fisher. Using the 6.0 M solution, stock solutions were made by dividing the desired concentration by $6.0 \mathrm{M}$ and multiplying by $1000 \mathrm{ml}$ to determine the volume needed for a $1.0 \mathrm{~L}$ solution. Table 3.1 shows the chemicals used. 


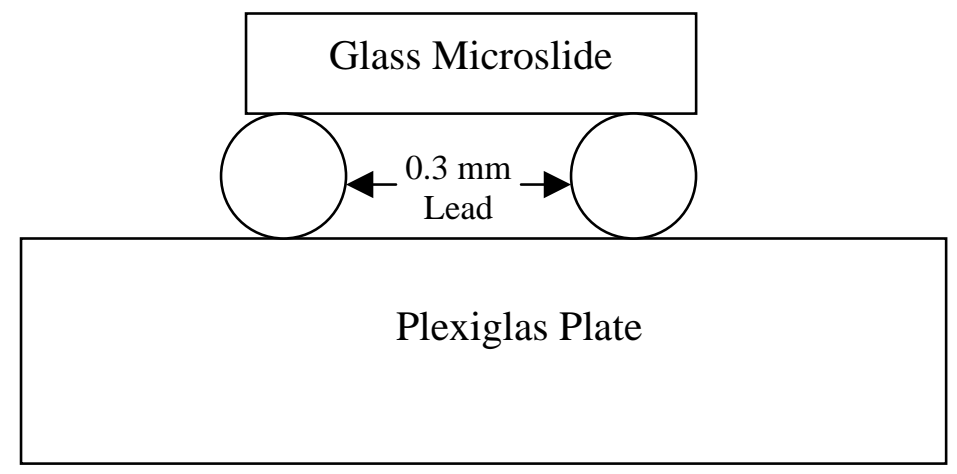

Figure 3.4. Set-up for Silica Gel Preparations. 
Table 3.1. Chemicals used for the BZ Reaction

\begin{tabular}{|c|c|c|}
\hline Chemicals & Chemical Formula & Molecular Weights \\
\hline Sodium Bromate & $\mathrm{NaBrO}_{3}$ & $150.9 \mathrm{~g} / \mathrm{mole}$ \\
\hline Malonic Acid & $\mathrm{MA}$ & $104.06 \mathrm{~g} / \mathrm{mole}$ \\
\hline Sodium Bromide & $\mathrm{NaBr}$ & $102.9 \mathrm{~g} / \mathrm{mole}$ \\
\hline Sulfuric Acid & $\mathrm{H}_{2} \mathrm{SO}_{4}$ & $98.08 \mathrm{~g} / \mathrm{mole}$ \\
\hline
\end{tabular}

\subsubsection{Reaction Set-up}

The chemicals for the $\mathrm{BZ}$ reaction were pumped into the reaction container using an Ismatec SA peristaltic pump at a rate of $1.4 \mathrm{ml} / \mathrm{min}$ (see Figure 3.5). A $0.3 \mathrm{~mm}$ thick gel binding the ruthenium catalyst was placed in the reaction container. The reaction takes place within the gel. A projector connected to a computer projected the patterns onto the gel. A concave lens was connected to the projector to allow the projected image to fit on the gel. A $460 \mathrm{~nm}$ filter was used on the camera and in front of the projector which is the wavelength that excites the ruthenium complex. A beam splitter is used with $75 \%$ of light going to the gel and $25 \%$ of the light going to a light intensity meter. The camera captures the images which are recorded and analyzed. 


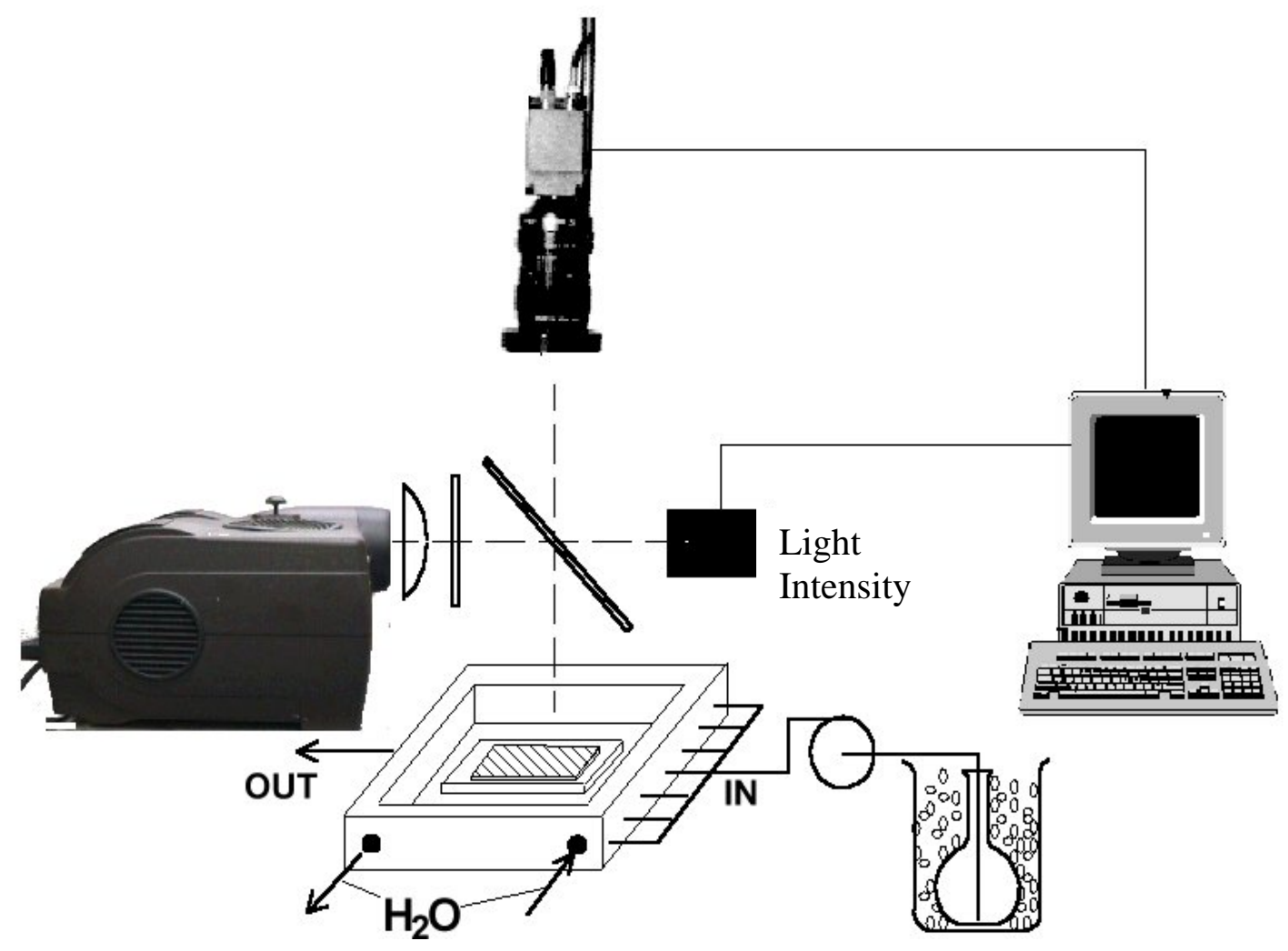

Figure 3.5. Reaction set-up for light sensitive BZ reaction. 


\subsubsection{Experiments}

\subsubsection{Ruthenium Catalyzed Silica Gel BZ Reactions with Light Perturbations}

The silica gel was prepared according to Section 3.2.1. The solutions for the BZ reaction $\left(\mathrm{NaBrO}_{3}, \mathrm{NaBr}, \mathrm{MA}\right.$, and $\left.\mathrm{H}_{2} \mathrm{SO}_{4}\right)$ were prepared according to Section 3.2.2. BrMA is also needed for the $\mathrm{BZ}$ reaction and is made according to reactions 3.4-3.5.

$$
\begin{aligned}
& 5 \mathrm{Br}^{-}+\mathrm{BrO}_{3}^{-}+6 \mathrm{H}^{+} \rightarrow 3 \mathrm{Br}_{2}+3 \mathrm{H}_{2} \mathrm{O} \\
& \mathrm{Br}_{2}+\mathrm{MA} \rightarrow \mathrm{BrMA}+\mathrm{Br}^{-} \\
& \mathrm{Br}_{2}+\mathrm{BrMA} \rightarrow \mathrm{Br}_{2} \mathrm{MA}+\mathrm{Br}^{-}
\end{aligned}
$$

BrMA is the desired product; however, if excess $\mathrm{Br}_{2}$ is present in the solution, reaction 3.6 occurs to give the unstable product $\mathrm{Br}_{2} \mathrm{MA}$, which therefore lowers the concentration of BrMA present in solution. For this reason, the solutions were kept in the refrigerator and mixed together in an ice bath to reduce the rate of reaction 3.6. Also, the $\mathrm{Br}^{-}$was pumped into the solution at a slow rate $(0.98 \mathrm{ml} / \mathrm{min})$ to prevent excess $\mathrm{Br}_{2}$ from forming.

To a $250 \mathrm{ml}$ Erlenmeyer flask sitting in a bucket of ice was added $2 / 3$ of the desired amount of doubly distilled water, $\mathrm{NaBrO}_{3}, \mathrm{MA}$, and $\mathrm{H}_{2} \mathrm{SO}_{4}$. The bucket containing the solution is then placed on a stir plate and $\mathrm{NaBr}$ is added using a Harvard '33' Syringe Pump. The $\mathrm{NaBr}$ solution was placed in a $30 \mathrm{ml}$ syringe and pumped into the solution at a rate of $0.98 \mathrm{ml} / \mathrm{min}$. The solution was then diluted to the mark with doubly distilled water.

The gel was placed in the reaction container and the solution was pumped into the container using an Ismatec SA peristaltic pump, at a rate of $1.4 \mathrm{ml} / \mathrm{min}$. See Figure 3.5 for the reactor set-up. 
Using a program designed for this experiment, a square pattern is projected onto the gel, allowing different intensities of light from the projector at each grid point. The light intensities range from 0 (dark) to 255 (maximum light). At zero light intensity, wave initiation begins and at maximum light intensity, wave behavior is suppressed. By varying the amount of light illuminating the gel, wave activity can be manipulated.

\subsubsection{Studies in Self-Organized Criticality (SOC) in the BZ System}

Using the same set-up as described in Section 3.2.4.1, further research into the self-organization of this system was undertaken. Noise patterns consisted of an array of square cells (Figure 3.6). Initially, the array was uniformly white, and no wave activity was supported. This is the subexcitable state of the experiment. At set intervals, the cells were randomly refreshed with positive and negative perturbations. If a cell is sufficiently dark, it reaches the excitable state, which is close to oscillatory conditions. At this excitable state, further positive perturbations added to the cell will cause nucleation of wave activity. Once the wave is initiated, it propagates until reaching surrounding white cells where it is suppressed.

The positive perturbations added to this system are noise patterns that are randomly generated by the computer. The cell is refreshed with a positive or negative perturbation at equal time intervals. Studies were carried out to show how the BZ reaction exhibits behavior similar to SOC. 


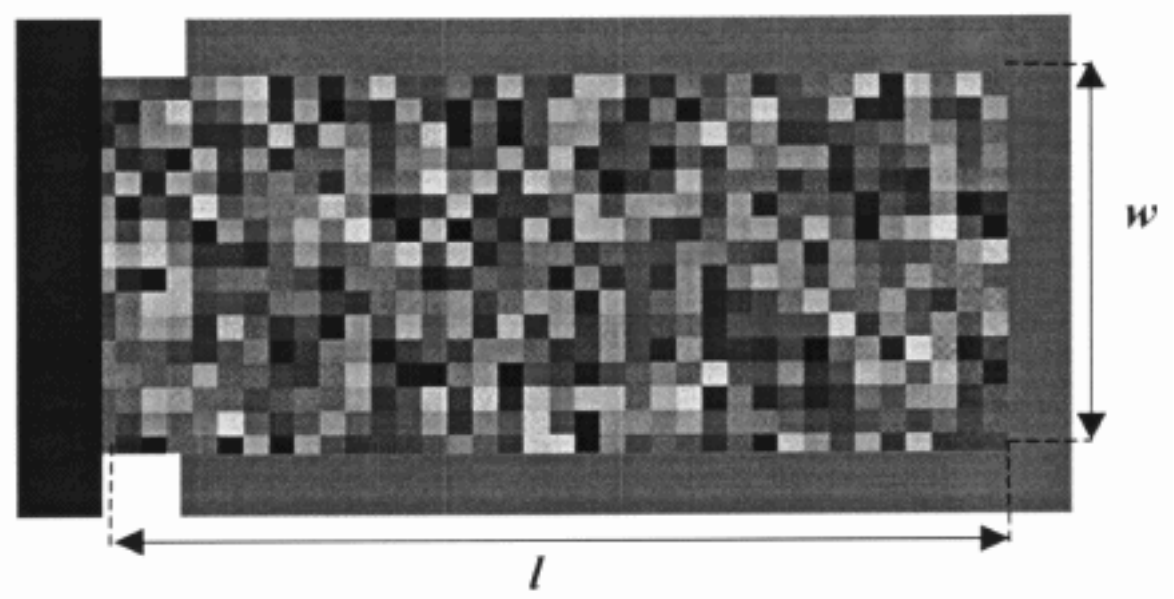

Figure 3.6. Diagram for the noise patterns. Figure from Ref 36. 


\subsubsection{Periodic Forcing}

Experiments are carried out similar to those described in Section 3.2.4.1, with the exception of the light patterns illuminating on the gel (see Figure 3.5). In this experiment, spiral waves are initiated in a dark region. As the wave propagates into the experimental medium, the light intensity is varied until the waves shrink at each end, thus establishing the excitability limit. Once the excitability limit is set, a fixed amplitude is set that refreshes the medium to a light intensity either a few percent above the excitability limit or a few percent below. For positive perturbations above the excitability limit, waves grow and curve outward. For negative perturbations below the excitability limit, waves shrink inward. Wave activity is compared at different periods of refreshing the noise pattern. 


\section{Chapter 4}

\section{Discussion}

\subsection{Self-Organized Criticality Experiments}

A system must follow two characteristics to exhibit SOC behavior. One characteristic is the natural ability of a system to organize itself into a critical state. When a random sequence of perturbations is added to a system at the critical state, the system reaches a supercritical state. At the super critical state, an avalanche occurs and the system relaxes to a sub critical state. The other characteristic is behavior following a power law.

The second characteristic was fulfilled in the power law shown in Figure 4.1, which indicates that waves of all sizes are possible in the noisy BZ system. This log-log plot follows eq 4.1 with a negative slope of -2.0 for both the experimental and computational systems,

$$
\log p(s)=\log (s)^{-2}
$$

where $\mathrm{p}(\mathrm{s})$ is the probability of a wave of size $\mathrm{s}$. To calculate the size of the wave, segments of the wave are taken at time $\Delta t$. The areas of these segments are calculated in pixel size. This area is multiplied by $\Delta \mathrm{t}$ to give the volume of that segment. The volumes for each segment of the wave are added to give a total volume of the wave. A pictorial diagram for this process is shown in Figure 4.2.

Noise patterns consisted of an array of square cells as shown in Figure 3.6. Initially, the array was uniformly illuminated at a reference level, and no wave activity 
Figure 4.1. Power law for SOC experiments in the BZ reaction: experiment $(\mathrm{O})$ and computer simulations ( $\square$ ). Figure from Ref 42 . 


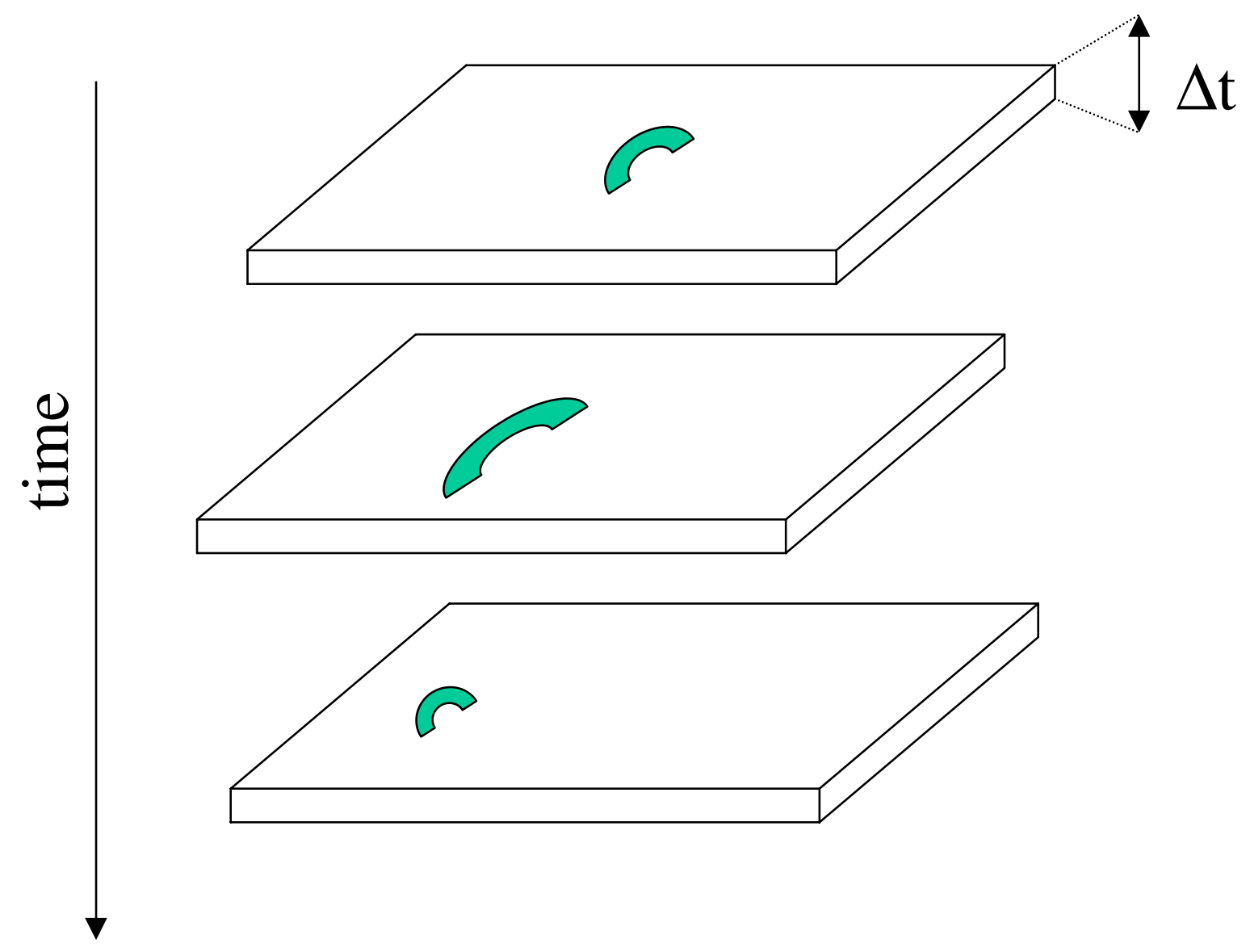

Figure 4.2. Pictorial diagram for wave volume calculations. 
was supported. This is the subexcitable state of the system. At set intervals, the cells were randomly refreshed with positive perturbations. When the cell is sufficiently dark, the system reaches the excitable state, which is close to oscillatory conditions. At this excitable state, further positive perturbations to the cell will cause wave initiation.

Once the wave is initiated, it propagates until reaching surrounding white cells where it is suppressed.

Table 4.1 lists the chemical concentrations used for SOC experiments. With these conditions, a wave would spontaneously initiate if the light intensity was set to zero. Wave activity was suppressed for a gray level of 255.

Table 4.1. Reaction Conditions for SOC Experiments

\begin{tabular}{|c|c|c|c|}
\hline Chemical & Stock Conc. (M) & Final Conc. (M) & Volume (ml) \\
\hline $\mathrm{NaBrO}_{3}$ & 1.0 & 0.28326 & 83.8 \\
\hline $\mathrm{NaBr}$ & 1.0 & N/A & 25.97 \\
\hline $\mathrm{MA}$ & 1.0 & 0.05418 & 52.5 \\
\hline $\mathrm{H}_{2} \mathrm{SO}_{4}$ & 6.0 & 0.46098 & 25.7 \\
\hline $\mathrm{BrMA}$ & N/A & 0.15582 & N/A \\
\hline Water & N/A & N/A & 62.03 \\
\hline
\end{tabular}




\subsection{Periodic Forcing}

The experiments were carried out in a similar manner to those described in Section 3.2.4.1, with the exception of the light patterns projected onto the gel (see Figure 3.5). In this experiment, spiral waves were initiated in a dark region. As the wave propagates into the medium, the light intensity is varied until the waves shrink at each end, which defines the excitability limit. Once the excitability limit is set, a fixed amplitude is set which refreshes the medium to a light intensity either a few percent above the excitability limit or a few percent below. For positive perturbations above the excitability limit, waves grow and curve outward. For negative perturbations below the excitability limit, waves shrink inward.

In this experiment, the chemical conditions needed to exhibit the above behavior are given in Table 4.2. It was found that when the positive perturbation was applied, the wave expanded in all directions and when the negative perturbation was applied, the wave receded at both free ends. Because the effect of the positive perturbations was greater, wave activity was sustained in the medium in which the perturbations alternated between positive and negative at constant amplitude. Another factor was the frequency at which the positive and negative perturbations were imposed. It was found that the optional conditions were low amplitude and low frequency. A computer simulation of this experiment is shown in Figure 4.3. 
Table 4.2. Reaction Conditions for Periodic Forcing Experiments

\begin{tabular}{|c|c|c|c|}
\hline Chemical & Stock Conc. (M) & Final Conc. (M) & Volume (ml) \\
\hline $\mathrm{NaBrO}_{3}$ & 1.0 & 0.28 & 82.5 \\
\hline $\mathrm{NaBr}$ & 1.0 & N/A & 25.0 \\
\hline $\mathrm{MA}$ & 1.0 & 0.05 & 50.0 \\
\hline $\mathrm{H}_{2} \mathrm{SO}_{4}$ & 6.0 & 0.162 & 13.0 \\
\hline $\mathrm{BrMA}$ & N/A & 0.15 & N/A \\
\hline Water & N/A & N/A & 79.5 \\
\hline
\end{tabular}

\subsection{Conclusion}

"After ten years of research and countless papers, the precise significance of selforganized criticality (SOC) is still controversial." ${ }^{43}$ Despite this controversy, SOC has provided insights into the dynamical behavior of many biological, physical and chemical systems. The chemical systems discussed in this thesis offer simple model systems from which an understanding of the much more complex biological systems can be developed. 
a

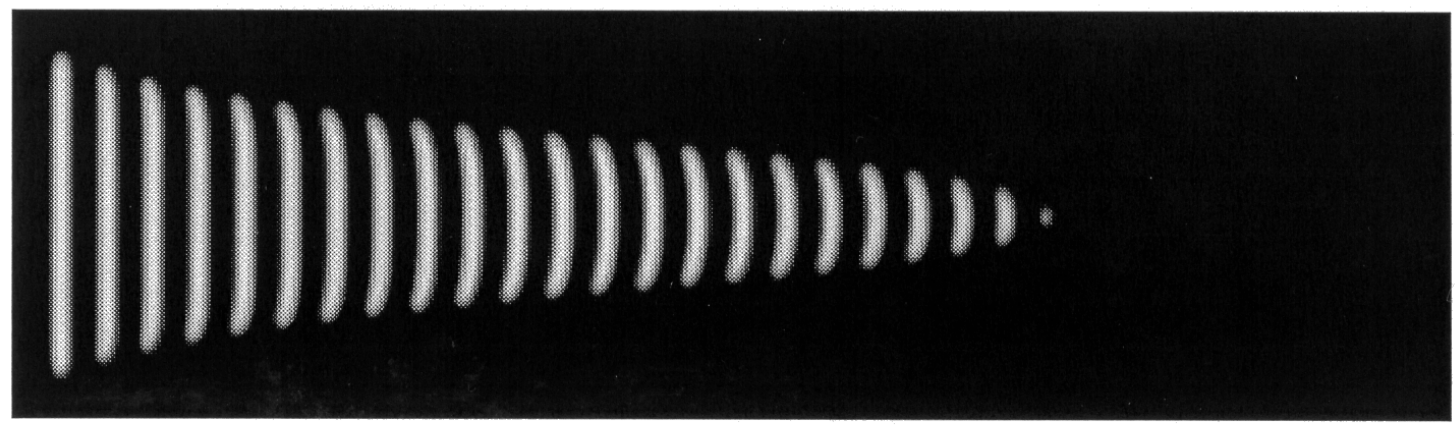

b

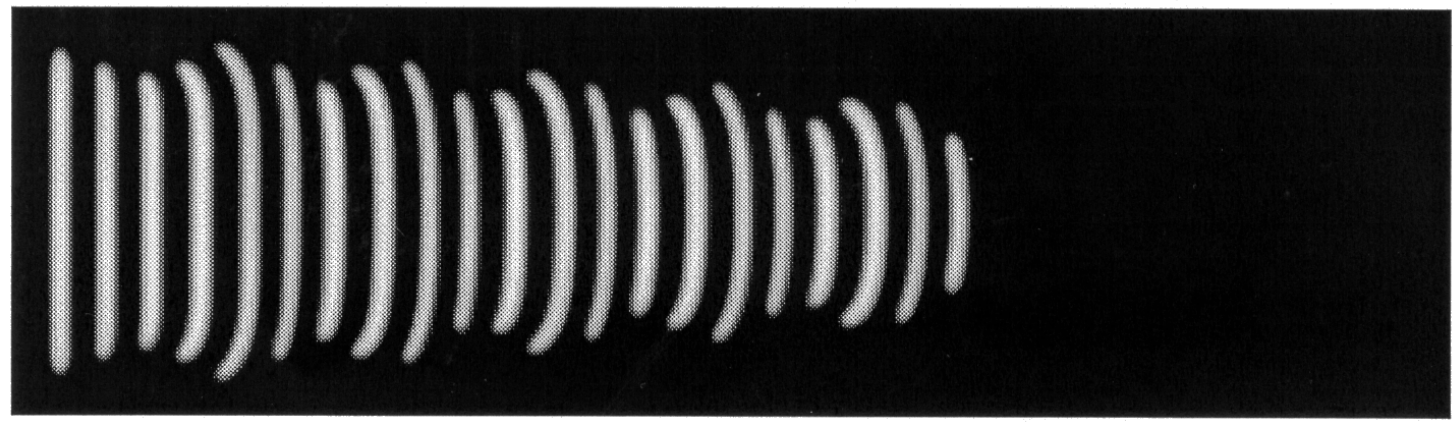

C

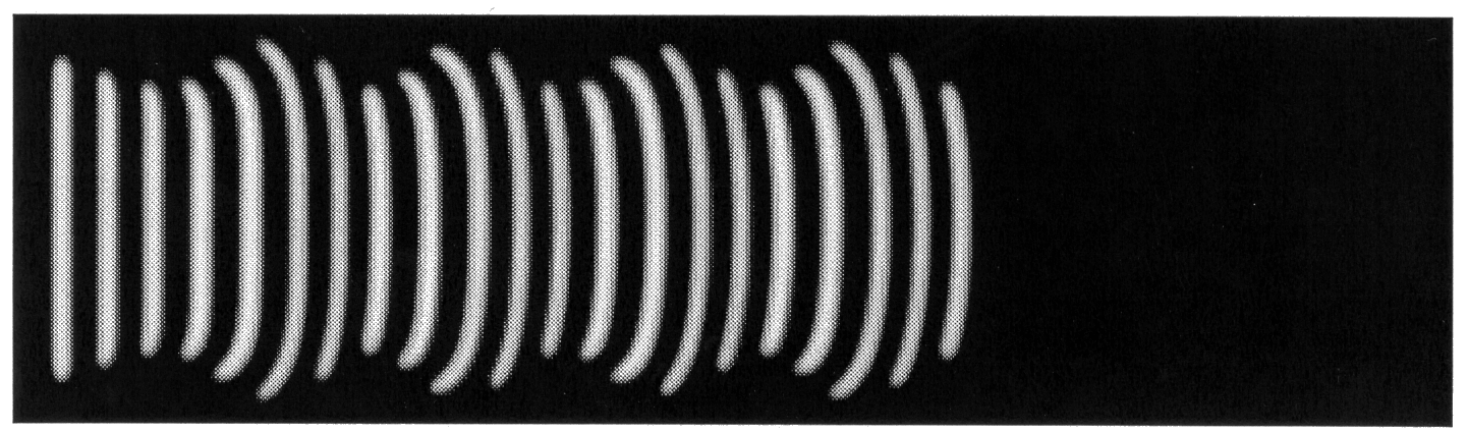

Figure 4.3. A computer simulation of periodic forcing experiments. Noise level: a) 0; b) 0.06; c) 0.06, Noise refresh period: b) 1.6875; c) 2.0625. Figure from Ref 44. 


\section{References}

1. Edblom, E. C., Orbán, M., Epstein, I. R. J. Am. Chem. Soc. 1986, 108, 2826.

2. Glisten, S. Text-Book of Physical Chemistry; D. Van Nostrand Company, Inc.: Pennsylvania, 1940; pp 1058.

3. Gáspár, V., Showalter, K. J. Am. Chem. Soc. 1987, 109, 4669.

4. Gáspár, V., Showalter, K. J. Phys. Chem. 1990, 94, 4973.

5. Bünau, G.V., Eigen, M. Z. Phys. Chem. 1962, 32, 27.

6. Reynolds, W. L. J. Am. Chem. Soc. 1958, 80, 1830.

7. Scott, S. K. Oscillations, Waves, and Chaos in Chemical Kinetics; Oxford University Press: Oxford, 1994; Chapter 3.

8. Field, R. J., Körös, E., Noyes, R. M. J. Am. Chem. Soc. 1972, 94, 8649.

9. Field, R. J., Noyes, R. M. J. Chem. Phys.1974, 60, 1877.

10. Krug, H-J, Pohlmann, L., Kuhnert, L. J. Phys. Chem. 1990, 94, 4862.

11. Reddy, M. K. R., Szlávik, Z., Nagy-Ungvarai, Zs., Müller, S. C. J. Phys. Chem. 1995, 99, 15081.

12. Kádár, S., Amemiya, T., Showalter, K. J. Phys. Chem. A 1997, 101, 8200.

13. Reddy, M. K. R., Nagy-Ungvarai, Zs., Müller, S. C. J. Phys. Chem.1994, 98, 12255.

14. Petrov, V., Ouyang, Q., Li, G., Swinney, H. L. J. Phys. Chem. 1996, 100, 18992.

15. Sørensen, P. G., Lorenzen, T., Hynne, F. J. Phys. Chem. 1996, 100, 19192.

16. Zhou, S., Wu, C. Macromolecules. 1996, 29, 4998.

17. Yoshida, R., Uchida, K., Kaneko, Y., Sakai, K., Kikuchi, A., Sakurai, Y., Okano, T. Nature. 1995, 374, 240.

18. Kawasaki, H., Namura, T., Miyamoto, K., Tokita, M. J. Chem. Phys. 1995, 103, 6241.

19. Shibayama, M., Mizutani, S., Nomura, S. Macromolecules. 1996, 29, 2019. 
20. Osada, Y., Okuzaki, H., Hori, H. Nature. 1992, 355, 242.

21. Shibuya, T., Yasunaga, H., Kurosu, H., Ando, I. Macromolecules. 1995, 28, 4377.

22. Hirai, M., Hirai, T., Sukumoda, A., Nemoto, H., Amemiya, Y., Kobayashi, K., Ueki, T. Faraday Soc. Trans. 1995, 91, 473.

23. Zhang, X., Li, Y., Hu, Z., Litter, C. L. J. Chem. Phys. 1995, 102, 551.

24. Hu, Z., Zhang, X., Li, Y. Science. 1995, 269, 525.

25. Tanaka,T. Phys. Rev. Lett. 1978, 40, 820.

26. Pavesi, L., Rigamonti, A. Phys. Rev. E. 1995, 51, 3318.

27. Brazel, C., Peppas, N. A. Macromolecules. 1995, 28, 8016.

28. Siegel, R. A. Modeling of Self Regulating Oscillatory Drug Delivery; K. Park, Eds.: Washington, D.C., 1997; 501-527.

29. Osada, Y., Gong, J. P., Sawahata, K. L. Macromol. Sci. Chem. 1991, A28, 1189.

30. Gáspár, V., Showalter, K. J. Am. Chem. Soc. 1987, 109, 4869.

31. Lee, K. J., Swinney, H. L. Phys. Rev. E. 1995, 51, 1899.

32. Yoshida, R., Takahashi,T., Yamaguchi, T., Ichijo, H. J. Am. Chem. Soc. 1996, 118, 5134.

33. Yoshida, R., Takahashi, T., Yamaguchi, T., Ichijo, H. Models in Chemistry. 1998, $135,409$.

34. Ghosh, P. K., Spiro, T. G. J. Am. Chem. Soc. 1980, 102, 5543.

35. Bak, P., Chen, K. Sci. Am. 1991, 264, 46.

36. Kádár, S., Wang, J., Showalter, K. Nature. 1998, 391, 770.

37. Bak, P., Tang, C., Wiesenfeld, K. Phys. Rev. A. 1988, 38, 364.

38. Zanette, D., Manrubia, S. Phys. Rev. Lett. 1997, 79, 323.

39. Jung, P. Phys. Rev. Lett. 1997, 78, 1723.

40. Sornette, A., Sornette, D. Europhys. Lett. 1989, 9, 197. 
41. Carlson, J. M., Langer, J. S. Phys. Rev. Lett. 1989, 62, 2632.

42. Wang, J., Kádár, S., Jung, P., Showalter, K. Phys. Rev. Lett., in press.

43. Vespignani, A., Zapperi, S. Phys. Rev. E. 1998, 57, 6345.

44. Wang, J., Kádár, S., Showalter, K., in preparation. 


\title{
Perturbation Studies of Excitable Media
}

\section{Lisa Elizabeth Seagraves}

\begin{abstract}
(Abstract)
Poly(N-isopropylacrylamide) (PNIPA) based systems are probably the most often studied polymer gels due to their dramatic change in volume, swelling and deswelling. Since this system has the best response to $\mathrm{pH}$ between 4 and 7 , the ferrocyanide-iodatesulfite (FIS) reaction, which exhibits $\mathrm{pH}$ oscillations between 4 and 7.5 in a continuously stirred tank reactor (CSTR), is a good candidate for studies of oscillatory gel systems.

This work also focused on two dynamical phenomena in the ruthenium catalyzed Belousov-Zhabotinsky (BZ) reaction. One is self-organized criticality and the other is periodic forcing and how they can be studied with the BZ reaction. Self-organized criticality is the ability of a system to organize itself into a critical state as a response to random perturbations. Periodic forcing gives rise to waves being sustained in a subexcitable medium by imposing periodic perturbations above and below the excitability limit.
\end{abstract}




\section{Vita}

The author was born on August 14, 1972 to Mr. and Mrs. David R. Seagraves.

She attended Miami Sunset Senior High School in Miami, Florida and graduated in 1990.

She received a Bachelor of Science degree in Chemistry from Purdue University in 1995.

The author is a candidate for the degree of Master of Science in Physical Chemistry at West Virginia University. 